\title{
IDUA mutational profile and genotype-phenotype relationships in UK patients with Mucopolysaccharidosis I
}

DOI:

10.1002/humu.23301

\section{Document Version}

Accepted author manuscript

Link to publication record in Manchester Research Explorer

\section{Citation for published version (APA):}

Ghosh, A., Mercer, J., Mackinnon, S., Yue, W. W., Church, H., Beesley, C. E., Broomfield, A., Jones, S., \& Tylee, K. (2017). IDUA mutational profile and genotype-phenotype relationships in UK patients with

Mucopolysaccharidosis I. Human Mutation. https://doi.org/10.1002/humu.23301

\section{Published in:}

Human Mutation

\section{Citing this paper}

Please note that where the full-text provided on Manchester Research Explorer is the Author Accepted Manuscript or Proof version this may differ from the final Published version. If citing, it is advised that you check and use the publisher's definitive version.

\section{General rights}

Copyright and moral rights for the publications made accessible in the Research Explorer are retained by the authors and/or other copyright owners and it is a condition of accessing publications that users recognise and abide by the legal requirements associated with these rights.

\section{Takedown policy}

If you believe that this document breaches copyright please refer to the University of Manchester's Takedown Procedures [http://man.ac.uk/04Y6Bo] or contact uml.scholarlycommunications@manchester.ac.uk providing relevant details, so we can investigate your claim.

\section{OPEN ACCESS}


IDUA mutational profile and genotype-phenotype relationships in UK patients with Mucopolysaccharidosis I

\author{
Arunabha Ghosh $(1,2)$ \\ Jean Mercer (1) \\ Sabrina Mackinnon (3) \\ Wyatt W Yue (3) \\ Heather Church (1) \\ Clare E Beesley (4) \\ Alex Broomfield (1) \\ Simon A Jones (1) \\ Karen Tylee (1)
}

1. Manchester Centre for Genomic Medicine, St Mary's Hospital, Manchester Academic Health Science Centre (MAHSC), Manchester, UK

2. School of Biological Sciences, Faculty of Biology, Medicine and Health, University of Manchester, UK

3. Structural Genomics Consortium, Nuffield Department of Medicine, University of Oxford

4. North East Thames Regional Genetics Service, Great Ormond Street Hospital for Children NHS Foundation Trust, London, UK

This article has been accepted for publication and undergone full peer review but has not been through the copyediting, typesetting, pagination and proofreading process, which may lead to differences between this version and the Version of Record. Please cite this article as doi: 10.1002/humu.23301.

This article is protected by copyright. All rights reserved. 


\section{Correspondence:}

Dr Arunabha Ghosh

Manchester Centre for Genomic Medicine

St Mary's Hospital

Oxford Road

Manchester

M13 9WL

0161276 12137/8

arunabha.ghosh@cmft.nhs.uk

Grant Sponsor: Not applicable (no grants were received for this work)

\section{ABSTRACT}

Mucopolysaccharidosis Type I is a lysosomal storage disorder with varying degrees of phenotypic severity caused by mutations in IDUA. Over 200 disease-causing variants in IDUA have been reported. We describe the profile of disease-causing variants in 291 individuals with Mucopolysaccharidosis Type I for whom IDUA sequencing was performed, focussing on the UK subset of the cohort. A total of 63 variants were identified, of which 20 were novel, and the functional significance of the novel variants is explored. The severe form of Mucopolysaccharidosis Type I is treated with haematopoietic stem cell transplantation, known to have improved outcomes with earlier age at treatment. Developing genotypephenotype relationships would therefore have considerable clinical utility, especially in the light of the development of newborn screening programs for Mucopolysaccharidosis Type I. Associations between genotype and phenotype are examined in this cohort, particularly in the context of the profile of variants identified in UK individuals. Relevant associations can be made for the majority of UK individuals based on the presence of nonsense or truncating variants as well as other associations described in this report. 


\section{KEYWORDS}

Mucopolysaccharidosis Type I, Hurler, Hurler-Scheie, Scheie, iduronidase, IDUA, genotypephenotype relationships, genotype-phenotype correlations, newborn screening

\section{INTRODUCTION}

The mucopolysaccharidoses are a subset of lysosomal storage disorders (LSDs) in which there are genetic deficiencies in enzymes involved in the degradation of glycosaminoglycans (GAGs), which are important components of connective tissue. Mutations in IDUA (MIM\# 252800) result in Mucopolysaccharidosis Type I (MPS I), which is inherited in an autosomal recessive manner and has an estimated incidence of 1 in 100,000 live births (Beck, et al., 2014). The IDUA gene is located at $4 \mathrm{p} 16.3$ and comprises 14 exons. IDUA codes for the enzyme $\alpha$-L-iduronidase which is required for the degradation of the GAGs dermatan and heparan sulfate. Deficiency of the enzyme leads to the accumulation of these GAGs in tissues throughout the body, playing a central role in the pathogenesis of MPS I.

MPS I is often classified into three categories based on phenotypic severity: Hurler (severe, OMIM 607014), Hurler-Scheie (intermediate, OMIM 607015) and Scheie (attenuated, OMIM 607016). In practice, there is a continuous spectrum between severe and attenuated phenotypes. MPS I Hurler usually presents in the first year of life (Cleary and Wraith, 1995) and follows a progressive and debilitating course. Without treatment, survival beyond 10 years is rare (Shapiro, et al., 1995). The phenotype is characterised by developmental delay and progressive central nervous system involvement marked by cognitive decline, alongside characteristic facial features, skeletal abnormalities, hepatosplenomegaly, corneal clouding and respiratory and cardiac disease (Beck, et al., 2014; Cleary and Wraith, 1995). At the other end of the spectrum, individuals with Scheie disease have a slowly progressive disorder with 
preserved intellectual ability. They can have a normal life span though they may develop joint disease, corneal opacity and valvular cardiac lesions. The symptoms of the intermediate form, Hurler-Scheie, are greatly variable though not associated with the progressive cognitive decline seen in Hurler patients.

Two approved treatments for MPS I exist: enzyme replacement therapy (ERT) and haematopoietic stem cell transplantation (HSCT). ERT is normally used for patients with more attenuated disease but is unable to cross the blood-brain barrier and cannot treat the central nervous system manifestations of the severe form of MPS I. HSCT is therefore the treatment of choice for individuals with Hurler syndrome to preserve cognition (de Ru, et al., 2011). Earlier age at HSCT is associated with improved outcomes (Aldenhoven et al. 2015b).

Over 200 disease-causing variants in IDUA have been reported to date (Human Gene Mutation Database, HGMD) (Stenson, et al., 2014), of which the most common are p.(Trp402Ter) and p.(Gln70Ter) (Pineda, et al., 2014). The majority of these are missense or nonsense variants, but splicing variants, deletions, insertions, and complex rearrangements are reported (HGMD). So far, confident phenotypic prediction is only possible when individuals have two nonsense mutations, being associated with a Hurler phenotype (Terlato and Cox, 2003). In addition, the presence of polymorphisms may modify the expression of mutations (Beesley, et al., 2001; Scott, et al., 1993). Despite this, there would be great clinical utility in focussing on the ability to stratify severe (Hurler) and attenuated (HurlerScheie or Scheie) phenotypes, as the former group are potential candidates for early HSCT. Early diagnosis of MPS I may be potentially improved by newborn screening, but identification of severely affected individuals likely to be suitable for HSCT presents a further challenge as infants are often oligosymptomatic at this stage. An understanding of 
genotype-phenotype relationships, particularly in the context of the mutational profile of a candidate population for newborn screening, is therefore useful.

We report the IDUA variants identified in 291 individuals with Mucopolysaccharidosis Type I, including 20 novel variants for which we examine the functional relevance. In addition to describing the mutational profile of IDUA, we investigate the genotype-phenotype relationship, with particular focus on the UK cohort of MPS I.

\section{MATERIALS AND METHODS}

\section{Patients and classification into phenotypic groups}

DNA samples from 291 individuals with a biochemical diagnosis of MPS I were received from around the world between 1993-2015 (Figure 1). The majority of samples were for subjects from the UK and Ireland (Table 1a) and of white British ethnic origin (Table 1b). For the majority of individuals, a phenotypic group (Hurler, Hurler-Scheie or Scheie) had been assigned at the time of sample receipt, based on information from the referring clinician. In this study, three authors (AG, SAJ, JM) re-classified individuals as 'severe-phenotype' or 'attenuated-phenotype.' For individuals who had been reviewed in the lysosomal disorders clinic at Manchester, classification of a 'severe' phenotype was based on the presence of one or more of the following: presentation with clinical features of MPS I and diagnosis before 12 months of age; significant developmental delay in a child with clinical features of MPS I under 30 months of age; sibling of a child with MPS I also classified as 'severe-phenotype.' For the remaining individuals, those originally described as 'Hurler' were re-classified as 'severe-phenotype', and those originally described as 'Hurler-Scheie' or 'Scheie' were reclassified as 'attenuated-phenotype.' Both a complete genotype and phenotypic classification was available for a total of 279 individuals.

This article is protected by copyright. All rights reserved. 


\section{IDUA sequencing}

Genomic DNA was isolated from peripheral blood cells or cultured skin fibroblasts using standard protocols. All samples were analysed by bidirectional Sanger sequencing of the IDUA gene. IDUA exons and adjacent intron regions were amplified by PCR reactions and then sequenced by standard procedures within our centre. Reference sequences used were NM_000203.3 and NG_008103.1 for non-coding variants. Variants are described using current Human Genome Variation Society (HGVS) recommended nomenclature, (den Dunnen, et al., 2016) but commonly used older nomenclatures for previously published variants are given in Supp. Table S1 for reference. All novel variants have been submitted to the Leiden Open Variation Database version 3.0 at https://databases.lovd.nl/shared/genes/IDUA.

\section{Iduronidase enzyme activity}

For 158 out of 291 individuals where the biochemical diagnosis was made or confirmed in Manchester, the activity of $\alpha$-L-iduronidase was measured on leucocytes isolated from peripheral blood as part of the laboratory diagnostic protocol for MPS I. Leucocyte lysates were prepared and assayed for $\alpha$-L-iduronidase activity using the fluorescent substrate 4methylumbelliferyl- $\alpha$-L-iduronide (Glycosynth, Warrington, UK) as described previously (Stirling, et al., 1978). Iduronidase activity was expressed as $\mu \mathrm{mol} / \mathrm{g}$ total $\mathrm{protein} / \mathrm{hr}$ (normal reference range $10-50$, heterozygote range $5-25)$.

\section{Structural interpretation of variants}

3-dimensional structural analysis of the iduronidase protein was performed for missense variants. The crystal structure of human IDUA (PDB code $4 \mathrm{MJ} 2$ ) was visually inspected 
using the program ICM-Pro v3.8 (Molsoft, LLC), to interpret the impact of missense mutations not previously reported in the literature.

\section{Analysis}

The proportion of individuals in the cohort with severe or attenuated phenotypes was determined and further subdivided according to geographical origin of sample (Table 1a). Ethnicity is indicated where known (Table 1b). Allele frequencies within the cohort were calculated for each IDUA variant identified and compared to their reported minor allele frequencies within ExAC (hg19; exac.broadinstitute.org). Variants previously reported as disease-associated were identified by searching the Human Gene Mutation Database (HGMD, www.hgmd.org) and by literature review. Phylogenetic conservation for missense variants was estimated by using the Clustal Omega program (via www.uniprot.org) to align the amino acid sequence of IDUA orthologues in seven vertebrate species (human, chimpanzee, dog, mouse, chicken, African clawed frog and zebrafish) with an evolutionary divergence time of approximately 430 million years.

\section{In silico analysis}

A number of in silico tools were used to predict the effects of identified variants on protein function. These included independent function prediction scores (SIFT, MutationTaster, PolyPhen-2, FATHMM) and ensemble scores (KGGSeq, REVEL). The 'Sorting Tolerant From Intolerant' algorithm (SIFT) examines the effects of amino acid substitutions using a sequence homology approach (Kumar, et al., 2009). Mutation Taster predicts the diseasecausing potential of an alteration at DNA level. One of three models are used: for noncoding or synonymous alterations, single amino acid substitutions, or alterations involving more than one amino acid. The software takes into account both the predicted effects of the alteration on 
protein function (including effects on splice sites) and the frequency of the variant in the HapMap population, 1000 Genomes, or its presence as a known pathogenic variant in ClinVar. (Schwarz, et al., 2014). Polyphen-2 is an automated tool that predicts the impact of an amino acid substitution based on sequence features, phylogenetic information, and structural features (Adzhubei, et al., 2010). Functional Analysis Through Hidden Markov Models (FATHMM) predicts the functional effects of missense variants by combining sequence conservation with probabilistic models (Hidden Markov Models). The model weighted for human mutations incorporates 'pathogenicity weights,' which represent the overall tolerance of the protein or domain to mutations. A related tool, FATHMM-MKL (machine knowledge learning) allows predictions to be made for non-coding variants by integrating nucleotide-based sequence conservation measures with annotations from the Encyclopedia of DNA Elements (ENCODE) which aims to identify all functional elements of the genome including those outside protein-coding regions (Shihab, et al., 2015). KGGSeq (Knowledge-based mining platform for Genomic and Genetic studies using Sequence data) allows prediction of pathogenicity of variants by combining existing functional scores of variants from multiple algorithms (including SIFT, Polyphen-2, FATHMM and others) using a logistic regression model (Li, et al., 2013). REVEL (rare exome variant ensemble learner) is an ensemble method that predicts pathogenicity of missense variants based on multiple individual prediction tools. Pre-computed scores are available for all possible human missense variants (Ioannidis, et al., 2016). The inputs and parameters used for these in silico tools are given in Supp. Table S2.

This article is protected by copyright. All rights reserved. 


\section{Genotype-phenotype relationships}

Associations between genotypes and phenotypic groups were examined with the emphasis on identifying variants associated with a severe phenotype, with the assumption that the presence of two such variants would result in a severe phenotype. Potential genotypephenotype relationships established by this approach were further evaluated within a separate cohort of UK MPS I patients. This cohort was originally described by (Beesley, et al., 2001), with updated genotypic and phenotypic information (Clare Beesley, personal communication).

\section{RESULTS}

\section{Variants identified}

A total of 63 different IDUA variants were identified (Supp. Table S1), of which 43 have been previously reported in the literature and 20 were novel (Table 2). Of these, 27 were missense variants, 11 were nonsense variants, 10 were frame shift deletions, duplications or insertion/deletions, 5 were in-frame deletions or insertions, 7 were splice site variants, 1 was an initiating codon change and 2 were large deletions (whole gene and exons $1 \& 2$ ). The latter two variants were identified in an individual who had severe MPS I and had a paternally inherited deletion of exons 1 and 2 and a whole gene deletion of IDUA secondary to maternal mosaicism (Breen, et al., 2016).

The majority of variants occurred only in single individuals in the cohort (UK: 20/38 variants, 52\%; all regions: 37/63 variants, 59\%), but this represented a minority of individuals overall (UK: 20/149, 13\%; all regions 27/286, 13\%). Over half of the variants identified in single individuals were either nonsense or truncating frameshift variants (UK: 12/20 variants, 
all regions 21/37 variants). The three most frequently occurring variants [p.(Trp402Ter), p.(Gln70Ter), and p.(Leu490Pro), Figure 2] accounted for $62 \%$ of alleles in UK individuals (all regions, 63\%). The variant p.(Arg628Ter) was not present in any UK or Ireland individuals but was identified in 14 individuals from other regions, accounting for $4.8 \%$ of alleles in all individuals. Supp. Figure S1 highlights all identified variants in the context of the whole gene alongside population frequency data of all listed IDUA variants in ExAC. The majority of variants identified in this cohort were not present in ExAC, and no variant had an allele frequency in ExAC greater than 0.065\% (Supp. Table S1).

IDUA variants at both alleles were identified in a total of 279 individuals for whom phenotypic information was also available. Of these, $76 \%$ had a severe phenotype and $24 \%$ had attenuated phenotypes (Table 1a). A total of 79 different genotypes were observed in the cohort (50 in the UK cohort, Supp. Table S3).

\section{Novel variants}

Twenty IDUA variants identified in this cohort have not been previously reported in the literature as disease-causing, and were not listed in HGMD or ExAC (Table 2). Two nonsense variants were identified. One variant $(\mathrm{c} .1456 \mathrm{G}>\mathrm{T})$, which was identified in a homozygous state in a severe-phenotype individual, is predicted to result in a premature termination codon at position 486, and to be associated with nonsense-mediated mRNA decay (NMD). The other (c.1898C $>$ A) was identified in a compound heterozygous state with a well described nonsense variant in a severe-phenotype individual. This variant is predicted to result in a premature termination codon at position 633 in exon 14/14 of IDUA. Though this may result in an only slightly truncated protein, there is evidence of a functional defect as this variant was identified in an individual with clinical features consistent with a severe 
phenotype, with biochemically confirmed iduronidase deficiency (Table 2). This would also be consistent with the existence of several previously reported disease-causing variants in the C-terminus of iduronidase, both in this cohort (Supp. Table S1) and in previous literature reports (Beesley, et al., 2001; Lee-Chen, et al., 2002; Saito, et al., 2014; Vazna, et al., 2009). These variants result in truncation of the non-catalytic (Ig-like) domain of the protein. This domain is required for protein stability and may also contribute to substrate orientation (Bie, et al., 2013).

One variant (c.1A>G) was identified in a homozygous state in a severe-phenotype individual. This variant is predicted to disrupt translation initiation, delaying the start of translation to the next downstream initiation site at position 133 in exon 4.

A further 5 novel truncating variants were identified ( 2 frameshift duplications, 2 frameshift deletions and 1 frameshift insertion/deletion). Two of these were identified in homozygous states in severe-phenotype individuals (c.506_513delinsGGAA, c.784_784delC). A further two variants were identified in a compound heterozygous state with previously described nonsense variants, one in a severe-phenotype individual (c.1277_1283dupGCCCCCA) and the other (c.1240_1240delA) in an individual with unknown phenotypic severity, but in whom enzyme deficiency was confirmed in Manchester. One truncating variant (c.17_24dupCCCGCGCC) was identified in an attenuated-phenotype individual in a compound heterozygous state with a novel missense variant (c.1871A $>\mathrm{T}$ ).

Four novel splice site variants were identified, all in severe-phenotype individuals. One of these (c.590-1G>C) was identified in a homozygous state, one (c.386-1G $>$ A) was observed both in a homozygous state and compound heterozygous state with a nonsense variant, and the others were compound heterozygous with a nonsense variant. The possible effects of 
these were examined with Human Splicing Finder (http://www.umd.be/HSF3/). The variant c. $1828 \mathrm{G}>\mathrm{C}$ could be misclassified as a missense variant but is in fact predicted to abolish the donor splice site at the end of exon 13 . The c. $158+1 \mathrm{G}>\mathrm{A}$ variant is predicted to disrupt the donor splice site at the end of exon 1 , while the c.590-1G>C variant is predicted to disrupt the acceptor splice site at the start of exon 6. Finally, the c.386-1G>A variant is predicted to disrupt the acceptor splice site at the start of exon 4.

The remainder of novel variants were either missense variants (6) or in-frame deletions (2). To further evaluate these variants, amino acid sequences from seven vertebrate species were aligned using Clustal Omega (Supp. Figure S2). Four out of six missense variants were at positions with fully conserved residues, and one was at a position with conservation between groups of strongly similar properties. One of the two in-frame deletions involved the loss of four fully conserved residues. Two variants [p.(Leu14Arg) and p.(Leu13_Ala15del)] involved only non-conserved residues.

In silico tools were used to assess the pathogenicity of the novel variants identified. These included both individual scores and ensemble methods, as individual scores do not necessarily perform consistently and ensemble tools may improve performance (Ioannidis, et al., 2016; Masica and Karchin, 2016). A recent study suggested that FATHMM had the highest discriminatory power for independent scores, and KGGSeq had the highest discriminatory power for ensemble scores. A more recently published ensemble method has been reported to have comparable performance and be particularly useful for assessing rare variants (Ioannidis, et al., 2016). However, the performance of such tools may vary between genes (Leong, et al., 2015). 
MutationTaster (www.mutationtaster.org) was used for all coding region variants and SIFT, Polyphen-2, FATHMM, KGGSeq and REVEL were used for coding region non-synonymous single nucleotide variants. Detailed results of these analyses are given in Supp. Table S4 and key predictions are summarized for novel variants in Table 2 and all variants in Supp. Table S1. MutationTaster predicted all but three of the novel variants assessed to be disease causing. The three variants predicted to be 'polymorphisms' were the missense variant p.(Leu14Arg) and the in-frame deletions c.36_44delGCTCCTGGC [p.(Leu13_Ala15del)] and c.523_534delTGGAACTTCGAG [p.(Trp175_Glu178del)].

All in silico tools predicted the novel missense variants p.(Thr179Lys), p.(Gly220Asp), p.(Gly265Asp) and p.(Leu396Arg) to be deleterious. Individual tools disagreed on the predicted pathogenicity of p.(Asp624Val) but both ensemble tools predicted the variant to be deleterious. Both individual and ensemble tools disagreed on the predicted pathogenicity of p.(Leu14Arg). In silico tools are generally designed to pick up on changes in protein stability and ligand binding, and as this variant is likely to affect the signal peptide, such tools may be less accurate for assessing this type of variant.

All 21 missense variants that had been previously reported as disease causing were predicted by at least one ensemble tool to be damaging, though the two methods disagreed for p.(Ala75Thr) and p.(Leu623Pro), and the REVEL score for p.(Gly208Val) was only 0.516 (75.4\% of disease causing variants and $10.9 \%$ of neutral variants have a REVEL score above 0.5) (Ioannidis, et al., 2016).

Three other in-frame variants (c.46_57delTCGCTCCTGGCC, c.398_403delTGGGCA, c.878_889dupCCCCCATTTACA) were identified in the overall cohort and all were predicted not to be damaging by MutationTaster (Supp. Table S1), but these have been 
established as disease causing variants, in some cases in multiple reports (Beesley, et al., 2001; Bunge, et al., 1994; Lee-Chen, et al., 2002; Oussoren, et al., 2013; Venturi, et al., 2002; Yogalingam and Hopwood, 2001).

\section{Structural interpretation of novel missense variants}

The six novel missense variants in this study were further examined in the context of the 2.1 $\AA$ resolution structure of wild type apo-iduronidase (protein data bank (PDB) accession 4MJ2) (Bie, et al., 2013), by inspecting the atomic environment surrounding the site of substitution (Figure 3).

p.(Gly220Asp)

This variant was identified in a compound heterozygous state with a known missense variant in a severe-phenotype individual. The glycine residue is part of a closely-packed beta sheet and is surrounded primarily by non-polar residues, close to an active site loop (Figure $3 b$ ). Introduction of the bulkier, positively charged aspartic acid would disrupt packing of the affected and neighbouring beta sheet, though the substitution site is distant from the active site.

p.(Leu396Arg)

This variant was identified in a homozygous state in an individual in whom biochemical confirmation of iduronidase deficiency was performed in Manchester, but no information on phenotypic group was available. The leucine residue is distant from the active site (Figure 3a). However, weak interactions with nearby non-polar residues may stabilise the adjacent helix and beta sheet (Figure 3c). Substitution with a bulky, positively charged arginine would alter the local charge environment.

This article is protected by copyright. All rights reserved. 
p.(Thr179Lys)

This variant was identified in a homozygous state in an attenuated-phenotype individual. The threonine residue immediately precedes the active site loop (Figure $3 \mathrm{~d}$ ). The local structural arrangement would be altered by the introduction of lysine with an extended side-chain and positive charge (Figure 3d). A variant at the same position, p.(Thr179Arg) has been reported in a homozygous state in individuals with severe phenotype (Wang, et al., 2012).

p.(Gly265Asp)

This variant was identified in a compound heterozygous state with the nonsense variant p.(Trp402Ter) in an attenuated-phenotype individual. The preceding residue (Lys264) is part of the substrate binding pocket (Figure 3e). Replacement of the small, neutral glycine with the bulkier, negatively charged aspartic acid may alter the substrate binding pocket. A variant at the same position, p.(Gly265Arg) has been reported with the common nonsense variant p.(Trp402Ter) in an individual with attenuated phenotype (Yogalingam, et al., 2004).

p.(Asp624Val)

This variant was identified in a compound heterozygous state with a frameshift duplication in an attenuated-phenotype individual. This residue is distant from the active site (Figure 3a). However, it stabilises a nearby loop through an ionic bond with Arg628 (Figure 3f).

Replacement with the hydrophobic valine would abolish this interaction, altering the local environment.

p.(Leu14Arg)

This variant was identified in a compound heterozygous state with a known splice site variant in a severe-phenotype individual. The leucine residue is not visible in the reported structure, but is part of the targeting signal peptide. The only other reported missense variant within the

This article is protected by copyright. All rights reserved. 
signal peptide, p.(Leu18Arg), was predicted to shorten the hydrophobic region of the signal peptide, and was associated with attenuated phenotype (Pasqualim, et al., 2015). The p.(Leu14Arg) variant reported here, resulting in the same amino acid change, may have a similar effect.

It has been previously suggested that variants close to the active site may be more deleterious than variants at the surface (Bertola, et al., 2011). The novel missense variants described here do not clearly fit with this pattern as only one of the three variants predicted to alter the active site was identified in a severe-phenotype individual [p.(Gly220Asp)]. The others were identified in attenuated-phenotype individuals in compound heterozygous states with well characterized truncating variants. Phenotypic information was only available for one variant that was distant from the active site [p.(Asp624Val)], which was identified in an attenuatedphenotype individual. Structural analysis was not possible for the variant p.(Leu14Arg) as this leucine residue was not present within the deposited structure. Most in silico tools predict this variant to be benign (Table 2) but the residue appears to be part of the signal peptide and this variant may therefore alter trafficking to the lysosome. Predicting the phenotypic severity associated with these missense variants remains challenging, with potential involvement of additional cellular factors beyond the mutated enzyme.

\section{Novel in-frame deletions}

The in-frame deletion p.(Leu13_Ala15del) was identified in a compound heterozygous state with p.(Trp402Ter) in a severe-phenotype individual. This variant would delete part of the signal peptide, likely compromising trafficking of the iduronidase protein to the lysosome. p.(Trp175_Glu178del) was identified in a homozygous state in an attenuated-phenotype 
individual. This variant deletes residues shortly before the active site loop. Deletion of these residues would likely disrupt the shape of the active site (Glu178 interacts with a number of charged and polar residues of the active site) and the overall protein stability and folding (Tyr175 and Phe177 both interact with nearby hydrophobic residues, contributing to the protein fold).

\section{DISCUSSION}

\section{Genotype-phenotype relationships}

Genotype-phenotype relationships were examined for individuals from all regions in whom both IDUA variants were identified and information on phenotypic group was available (Figure 1). In the UK cohort, homozygosity for c.1205G >A [p.(Trp402Ter)] was the most common genotype observed in severe-phenotype individuals, accounting for $29 \%$ of UK Hurler individuals (Table 3). In attenuated-phenotype individuals, the most frequently observed genotypes were c.1469T $>$ C [p.(Leu490Pro)] homozygous in Hurler-Scheie individuals, and c.1205G >A / c.590-7G >A in Scheie individuals (Table 3). The variant c.5907G $>$ A was observed exclusively in individuals with reported Scheie phenotype and was present in all but one individual with reported Scheie phenotype in the cohort. Homozygosity for p.(Trp402Ter) accounted for 89\% (69/78) of severe-phenotype individuals from Ireland and this is known to be the common mutation in the Irish travelling community (Murphy, et al., 2009). In other regions, the most common genotype observed in severe-phenotype individuals was homozygosity for c.1882C $>$ T [p.(Arg628Ter)] (45\% of Hurler individuals from other regions). 
For 52/145 (36\%) UK individuals, both alleles were nonsense variants (all regions: 143/279, $51 \%$ ). All of these were severe-phenotype individuals, and no attenuated-phenotype individual had two nonsense variants. Both alleles were nonsense variants in 51\% of UK Hurler individuals (all regions: 68\%). Five nonsense variants identified in this cohort [p.(Arg619Ter), p.(Arg621Ter), p.(Trp626Ter), p.(Arg628Ter) and p.(Ser633Ter)] are in exon 14 of IDUA and are predicted to result in a slightly truncated protein (Supp. Table S1). Four of these have been reported previously in association with a severe phenotype (Supp. Table S1), and p.(Ser633Ter) is a novel mutation identified in this cohort.

Ten frameshift variants were identified in this cohort, all of which were predicted to result in NMD (Supp. Table S1). In 52 UK individuals, both alleles were either nonsense variants or frameshift variants (all regions: 143 individuals), and this accounted for 58\% of all UK severe-phenotype individuals (all regions: 68\%). No attenuated-phenotype individuals had a genotype where both alleles were nonsense or frameshift variants. In contrast, $56 \%$ of UK attenuated-phenotype individuals (all regions: 44\%) had at least one nonsense or frameshift variant. Overall this is consistent with previous reports that two 'null' variants are associated with a severe phenotype.

Genotype-phenotype relationships for other variants were further examined in the cohort with the emphasis of identifying variants associated with severe phenotype. The process for this is shown in Figure 4. In short, variants identified in severe-phenotype individuals were considered to be either 'probably' or 'possibly' associated with severe phenotype depending on the number of individuals in whom the variant was identified. Variants that did not meet criteria for being associated with severe phenotype were further examined, and considered to 
be either 'probably' or 'possibly' associated with an attenuated phenotype depending on whether they were observed in a homozygous state in attenuated-phenotype individuals or compound heterozygous with severe-phenotype-associated variants, as well as the number of individuals in whom they were identified.

The resulting associations are shown in Table 4. The presence of two variants considered to be 'severe-phenotype-associated' accounted for 99\% (208/211) of severe-phenotype individuals (UK cohort: 101/102, 99\%). No attenuated-phenotype individuals had two variants considered to be 'severe-phenotype-associated.'

Six variants were not assigned an association by this method. Three variants were identified in individuals for whom phenotypic information was unavailable in this cohort: c.614G $>\mathrm{A}$ [p.(Cys205Tyr)], c.719A >G [p.(His240Arg)] and c.1187T>G [p.(Leu396Arg)]. The variant c.46_57delTCGCTCCTGGCC was identified in a homozygous state in an attenuatedphenotype individual, but also in a compound heterozygous state with p.(Trp402Ter) in a severe-phenotype individual. Similarly, c.1598C $>$ G [p.(Pro533Arg)] was identified in a homozygous state in 6 attenuated-phenotype individuals but also in a compound heterozygous state with p.(Trp402Ter) in a severe-phenotype individual. Previous reports have suggested that homozygosity for this variant is associated with attenuated phenotypes (Laradi, et al., 2005; Matte, et al., 2003; Scott, et al., 1995) but that compound heterozygosity with p.(Trp402Ter) is associated with a severe phenotype (Scott, et al., 1995). This holds true in our cohort, but this variant was also identified in a compound heterozygous state with the nonsense variant p.(Arg619Ter) in an attenuated-phenotype individual. Prediction of associated phenotype for this variant may therefore only be reliably made if observed in a 
homozygous state, when it is associated exclusively with attenuated phenotypes in our cohort. One variant, c.623G $>$ T [p.(Gly208Val)] was identified in a homozygous state in both a severe-phenotype individual and an attenuated-phenotype individual. Both individuals were from the Middle East and had been referred by clinicians in their country of origin. The severe-phenotype individual had been reviewed within the Manchester LSD service and phenotypic information was verified by the authors as described in 'Methods', whereas the other individual had not been reviewed in Manchester and further phenotypic information was not available.

The latter case highlights one of the limitations of making genotype-phenotype relationships within this cohort, which is that in some instances classification into phenotypic groups was based solely on information provided by referring clinicians, often from abroad. However, the majority of suggested associations (Table 4) remained unchanged when genotypephenotype relationships were based on a cohort limited to those individuals who were reviewed in the Manchester LSD service and whose phenotypic information was independently verified (Figure 1). The variants for which this was not possible are highlighted in Table 4. Notably, both c.623G $>$ T [p.(Gly208Val)] and c.46_57delTCGCTCCTGGCC were associated with severe phenotypes when only individuals in this limited cohort were considered.

To assess the potential utility of these genotype-phenotype relationships, the associations suggested were applied to test cohort derived from a previously published cohort of MPS I patients (Beesley, et al., 2001). This study described the variants identified in a cohort of 85 families with MPS I, and identified 9 common variants. Phenotypic information was 
available for a subset of individuals in whom neither or only one variant was a common variant. Up to date genotypes and phenotypic classification was obtained for 31 such individuals in whom both IDUA variants were identified (Clare Beesley, personal communication) and this was used as the test cohort (Supp. Table S5).

Nonsense or frameshift truncating variants were considered to be severe-phenotype associated, and for the remainder associations were as listed in Table 4. Two 'probably' or 'possibly' severe-phenotype-associated variants were predicted to result in severe phenotype, and one or more 'probably' or 'possibly' attenuated-phenotype variants were predicted to result in attenuated phenotype. In 10 out of 31 individuals, no prediction was made as variants were either unknown within our cohort, or had not been assigned an association. However, in the remaining individuals the predicted phenotypic severity matched the reported clinical phenotype in all cases (Table 5). It should be noted that the test cohort did not contain any individuals in whom both alleles were one of 9 'common variants' (Supp. Table S5). Eight of these (all except p.(Pro533Arg)) were assigned a phenotypic association (Table 4). In our cohort, $52 \%$ of UK individuals with known phenotype and genotype had a combination of two of these variants (all regions, 57\%). Prediction of phenotypic severity is expected to be possible for individuals with two such variants, and the results of phenotype prediction in the test cohort suggest that it may also be possible in a significant proportion of remaining individuals.

The test cohort included an individual who was homozygous for c.623G $>$ T [p.(Gly208Val)], a variant for which phenotypic association was not assigned (Table 4). Interestingly, this individual had a severe phenotype, consistent with the observation of a severe phenotype in 
the individual in our cohort with the same genotype, whose phenotypic information could be independently verified. As seen in our cohort, the variant c.46_57del12 was identified in association with both severe and attenuated phenotypes.

There remain limitations to the approaches used here to develop genotype-phenotype relationships. One is the consistency of clinical assessment of phenotypic severity, as already discussed. A second is that the approach used here only considers the influence of true pathogenic variants on phenotypic severity, but polymorphisms in the IDUA gene may also play a role and are not reported here. This could be particularly important for missense mutations, for which phenotypic associations are difficult to characterize. This limitation is likely to also apply to other genotype-phenotype datasets including registry data, where additional variants may not be reported if both pathogenic variants are known. Further investigation into the influence of polymorphisms in large datasets such as this will be of value, particularly with the with the development of newborn screening programmes for MPS I.

\section{Concluding remarks}

A large array of IDUA variants is observed in individuals with MPS I. Many of these have been identified only in single families. Despite this, the mutational profile of IDUA is dominated by commonly occurring variants, particularly in the UK and Ireland where homozygosity for p.(Trp402Ter) is frequently observed. Nonsense variants and other variants predicted to result in severely truncated protein or NMD are associated with a severe 
phenotype, and account for the majority of individuals with severe phenotypes. Genotypephenotype relationships for other variants such as missense variants are more difficult to make on the basis of in silico tools, structural interpretation and other a priori evidence, but for certain variants associations based on observed genotypes and phenotypes can be made. A minority of variants observed in this cohort are associated with heterogeneous phenotypes. Despite these limitations, genotype-phenotype relationships can be made for the majority of UK MPS I individuals, largely due to the preponderance of well characterized common variants and truncating variants. Understanding the mutational profile within the UK in this way is potentially relevant to the development of newborn screening, as despite the large number of variants, the population of interest (UK individuals with severe phenotype) are likely to have a well characterized genotype. Though the phenotypic associations suggested for specific variants are likely to be equally applicable in different countries, the proportion of individuals for whom genotype-phenotype relationships can be made will vary according to the mutational profile in the relevant population, and this may be more difficult in countries where there is greater genetic heterogeneity (Venturi, et al., 2002). For individuals in whom the genotype-phenotype relationship is not well characterized, further evaluation, such as with analysis of fibroblast enzyme activity, may be required (Kingma, et al., 2013).

The genotype-phenotype relationships developed in this cohort will continue to be refined as further genetic testing is performed in Manchester for additional MPS I individuals, including by next-generation sequencing (Ghosh, et al., 2017), and with further investigation of the influence of non-pathogenic variants. More international data from sources such as the MPS I registry may be of additional value in clarifying the phenotype associated with certain variants.

This article is protected by copyright. All rights reserved. 


\section{ACKNOWLEDGEMENTS}

We thank Bill Newman and Siddharth Banka for useful discussions on the project and Victor

Faundes for advice on the use of in silico prediction tools.

\section{REFERENCES}

Adzhubei IA, Schmidt S, Peshkin L, Ramensky VE, Gerasimova A, Bork P, Kondrashov AS, Sunyaev SR. 2010. A method and server for predicting damaging missense mutations. Nat Methods 7(4):248-9.

Beck M, Arn P, Giugliani R, Muenzer J, Okuyama T, Taylor J, Fallet S. 2014. The natural history of MPS I: global perspectives from the MPS I Registry. Genetics in Medicine 16(10):759-765.

Beesley CE, Meaney CA, Greenland G, Adams V, Vellodi A, Young EP, Winchester BG. 2001. Mutational analysis of 85 mucopolysaccharidosis type I families: frequency of known mutations, identification of 17 novel mutations and in vitro expression of missense mutations. Hum Genet 109(5):503-11.

Bertola F, Filocamo M, Casati G, Mort M, Rosano C, Tylki-Szymanska A, Tuysuz B, Gabrielli O, Grossi S, Scarpa M, Parenti G, Antuzzi D, Dalmau J, Di Rocco M, Dionisi Vici C, Okur I, Rosell J, Rovelli A, Furlan F, Rigoldi M, Biondi A, Cooper DN, Parini R. 2011. IDUA mutational profiling of a cohort of 102 European patients with mucopolysaccharidosis type I: identification and characterization of 35 novel alpha-L-iduronidase (IDUA) alleles. Hum Mutat 32(6):E2189-210.

Bie H, Yin J, He X, Kermode AR, Goddard-Borger ED, Withers SG, James MN. 2013. Insights into mucopolysaccharidosis I from the structure and action of alpha-L-iduronidase. Nat Chem Biol 9(11):739-45.

Breen C, Mercer J, Jones SA, Jahic A, Heptinstall L, Tylee K, Newman WG, Beetz C. 2016. Maternal mosaicism for IDUA deletion clarifies recurrence risk in MPS I. Hum Genome Var 3:16031.

Bunge S, Kleijer WJ, Steglich C, Beck M, Zuther C, Morris CP, Schwinger E, Hopwood JJ, Scott HS, Gal A. 1994. Mucopolysaccharidosis type I: identification of 8 novel mutations and determination of the frequency of the two common alpha-L-iduronidase mutations (W402X and Q70X) among European patients. Hum Mol Genet 3(6):861-6.

Cleary MA, Wraith JE. 1995. The presenting features of mucopolysaccharidosis type IH (Hurler syndrome). Acta Paediatr 84(3):337-9.

de Ru MH, Boelens JJ, Das AM, Jones SA, van der Lee JH, Mahlaoui N, Mengel E, Offringa M, O'Meara A, Parini R, Rovelli A, Sykora KW, Valayannopoulos V, Vellodi A, Wynn RF, Wijburg FA. 2011. Enzyme replacement therapy and/or hematopoietic stem cell transplantation at diagnosis in patients with mucopolysaccharidosis type I: results of a European consensus procedure. Orphanet J Rare Dis $6: 55$.

den Dunnen JT, Dalgleish R, Maglott DR, Hart RK, Greenblatt MS, McGowan-Jordan J, Roux AF, Smith T, Antonarakis SE, Taschner PE. 2016. HGVS Recommendations for the Description of Sequence Variants: 2016 Update. Hum Mutat 37(6):564-9.

Ghosh A, Schlecht H, Heptinstall LE, Bassett JK, Cartwright E, Bhaskar SS, Urquhart J, Broomfield A, Morris AA, Jameson E, Schwahn BC, Walter JH, Douzgou S, Murphy H, Hendriksz C, Sharma R, Wilcox G, Crushell E, Monavari AA, Martin R, Doolan A, Senniappan S, Ramsden SC, Jones SA, Banka S. 2017. Diagnosing childhood-onset inborn errors of metabolism by next-generation sequencing. Archives of Disease in Childhood.

Ioannidis NM, Rothstein JH, Pejaver V, Middha S, McDonnell SK, Baheti S, Musolf A, Li Q, Holzinger E, Karyadi D, Cannon-Albright LA, Teerlink CC, Stanford JL, Isaacs WB, Xu J, Cooney KA, Lange EM, Schleutker J, Carpten JD, Powell IJ, Cussenot O, Cancel-Tassin G, Giles GG, MacInnis RJ, Maier C, Hsieh CL, Wiklund F, Catalona WJ, Foulkes WD, Mandal D, Eeles RA, Kote-Jarai Z, Bustamante CD, Schaid DJ, Hastie T, Ostrander EA, Bailey-Wilson JE, Radivojac P, Thibodeau SN, Whittemore AS, Sieh W. 2016. REVEL: An Ensemble Method for Predicting the Pathogenicity of Rare Missense Variants. Am J Hum Genet 99(4):877-885.

Kingma SD, Langereis EJ, de Klerk CM, Zoetekouw L, Wagemans T, L IJ, Wanders RJ, Wijburg FA, van Vlies N. 2013. An algorithm to predict phenotypic severity in mucopolysaccharidosis type I in the first month of life. Orphanet J Rare Dis 8:99. 
Kumar P, Henikoff S, Ng PC. 2009. Predicting the effects of coding non-synonymous variants on protein function using the SIFT algorithm. Nat Protoc 4(7):1073-81.

Laradi S, Tukel T, Erazo M, Shabbeer J, Chkioua L, Khedhiri S, Ferchichi S, Chaabouni M, Miled A, Desnick RJ. 2005. Mucopolysaccharidosis I: Alpha-L-Iduronidase mutations in three Tunisian families. J Inherit Metab Dis 28(6):1019-26.

Lee-Chen GJ, Lin SP, Chen IS, Chang JH, Yang CW, Chin YW. 2002. Mucopolysaccharidosis type I: Identification and characterization of mutations affecting alpha-L-iduronidase activity. J Formos Med Assoc 101(6):425-8.

Leong IU, Stuckey A, Lai D, Skinner JR, Love DR. 2015. Assessment of the predictive accuracy of five in silico prediction tools, alone or in combination, and two metaservers to classify long QT syndrome gene mutations. BMC Med Genet 16:34.

Li M-X, Kwan JSH, Bao S-Y, Yang W, Ho S-L, Song Y-Q, Sham PC. 2013. Predicting Mendelian DiseaseCausing Non-Synonymous Single Nucleotide Variants in Exome Sequencing Studies. PLOS Genetics 9(1):e1003143.

Masica DL, Karchin R. 2016. Towards Increasing the Clinical Relevance of In Silico Methods to Predict Pathogenic Missense Variants. PLoS Comput Biol 12(5):e1004725.

Matte U, Yogalingam G, Brooks D, Leistner S, Schwartz I, Lima L, Norato DY, Brum JM, Beesley C, Winchester B, Giugliani R, Hopwood JJ. 2003. Identification and characterization of 13 new mutations in mucopolysaccharidosis type I patients. Mol Genet Metab 78(1):37-43.

Murphy AM, Lambert D, Treacy EP, O'Meara A, Lynch SA. 2009. Incidence and prevalence of mucopolysaccharidosis type 1 in the Irish republic. Arch Dis Child 94(1):52-4.

Oussoren E, Keulemans J, van Diggelen OP, Oemardien LF, Timmermans RG, van der Ploeg AT, Ruijter GJG. 2013. Residual $\alpha$-l-iduronidase activity in fibroblasts of mild to severe Mucopolysaccharidosis type I patients. Molecular Genetics and Metabolism 109(4):377-381.

Pasqualim G, Ribeiro MG, da Fonseca GG, Szlago M, Schenone A, Lemes A, Rojas MV, Matte U, Giugliani R. 2015. p.L18P: a novel IDUA mutation that causes a distinct attenuated phenotype in mucopolysaccharidosis type I patients. Clin Genet 88(4):376-80.

Pineda T, Marie S, Gonzalez J, García AL, Acosta A, Morales M, Correa LN, Vivas R, Escobar X, Protzel A, Barba M, Ospina S, Corredor C, Mansilla S, Velasco HM. 2014. Genotypic and bioinformatic evaluation of the alpha-l-iduronidase gene and protein in patients with mucopolysaccharidosis type I from Colombia, Ecuador and Peru. Molecular Genetics and Metabolism Reports 1:468-473.

Saito S, Ohno K, Maita N, Sakuraba H. 2014. Structural and clinical implications of amino acid substitutions in alpha-L-iduronidase: insight into the basis of mucopolysaccharidosis type I. Mol Genet Metab 111(2):107-12.

Schwarz JM, Cooper DN, Schuelke M, Seelow D. 2014. MutationTaster2: mutation prediction for the deepsequencing age. Nat Meth 11(4):361-362.

Scott HS, Bunge S, Gal A, Clarke LA, Morris CP, Hopwood JJ. 1995. Molecular genetics of mucopolysaccharidosis type I: diagnostic, clinical, and biological implications. Hum Mutat 6(4):288302.

Scott HS, Nelson PV, Litjens T, Hopwood JJ, Morris CP. 1993. Multiple polymorphisms within the alpha-Liduronidase gene (IDUA): implications for a role in modification of MPS-I disease phenotype. Hum Mol Genet 2(9):1471-3.

Shapiro EG, Lockman LA, Balthazor M, Krivit W. 1995. Neuropsychological outcomes of several storage diseases with and without bone marrow transplantation. J Inherit Metab Dis 18(4):413-29.

Shihab HA, Rogers MF, Gough J, Mort M, Cooper DN, Day IN, Gaunt TR, Campbell C. 2015. An integrative approach to predicting the functional effects of non-coding and coding sequence variation. Bioinformatics 31(10):1536-43.

Stenson PD, Mort M, Ball EV, Shaw K, Phillips A, Cooper DN. 2014. The Human Gene Mutation Database: building a comprehensive mutation repository for clinical and molecular genetics, diagnostic testing and personalized genomic medicine. Hum Genet 133(1):1-9.

Stirling JL, Robinson D, Fensom AH, Benson PF, Baker JE. 1978. Fluorimetric assay for prenatal detection of Hurler and Scheie homozygotes or heterozygotes. Lancet 1(8056):147.

Terlato NJ, Cox GF. 2003. Can mucopolysaccharidosis type I disease severity be predicted based on a patient's genotype? A comprehensive review of the literature. Genet Med 5(4):286-94.

Vazna A, Beesley C, Berna L, Stolnaja L, Myskova H, Bouckova M, Vlaskova H, Poupetova H, Zeman J, Magner M, Hlavata A, Winchester B, Hrebicek M, Dvorakova L. 2009. Mucopolysaccharidosis type I 
in 21 Czech and Slovak patients: mutation analysis suggests a functional importance of C-terminus of the IDUA protein. Am J Med Genet A 149A(5):965-74.

Venturi N, Rovelli A, Parini R, Menni F, Brambillasca F, Bertagnolio F, Uziel G, Gatti R, Filocamo M, Donati MA, Biondi A, Goldwurm S. 2002. Molecular analysis of 30 mucopolysaccharidosis type I patients: evaluation of the mutational spectrum in Italian population and identification of 13 novel mutations. Hum Mutat 20(3):231.

Wang X, Zhang W, Shi H, Qiu Z, Meng Y, Yao F, Wei M. 2012. Mucopolysaccharidosis I mutations in Chinese patients: identification of 27 novel mutations and 6 cases involving prenatal diagnosis. Clin Genet 81(5):443-52.

Yogalingam G, Guo XH, Muller VJ, Brooks DA, Clements PR, Kakkis ED, Hopwood JJ. 2004. Identification and molecular characterization of alpha-L-iduronidase mutations present in mucopolysaccharidosis type I patients undergoing enzyme replacement therapy. Hum Mutat 24(3):199-207.

Yogalingam G, Hopwood JJ. 2001. Molecular genetics of mucopolysaccharidosis type IIIA and IIIB: Diagnostic, clinical, and biological implications. Hum Mutat 18(4):264-81.

\section{DISCLOSURES}

Arunabha Ghosh declares travel assistance from Shire Plc, Biomarin Pharmaceutical, and consultancy fees from Alexion Plc. Alex Broomfield declares consulting fees from Genzyme corporation and Synageva. Simon Jones declares travel assistance, research grants and consultancy fees from Genzyme Corporation, Shire Plc, Biomarin Pharmaceutical, Alexion Pharmaceuticals and PTC Therapeutics. Jean Mercer, Sabrina Mackinnon, Wyatt Yue, Heather Church, Clare Beesley and Karen Tylee have nothing to disclose. 


\section{FIGURE LEGENDS}

Figure 1: Number of samples received for IDUA sequencing between 1993-2015, and numbers of individuals with two IDUA variants identified and phenotypic information known.

Key - H, Hurler; HS, Hurler-Scheie; S, Scheie

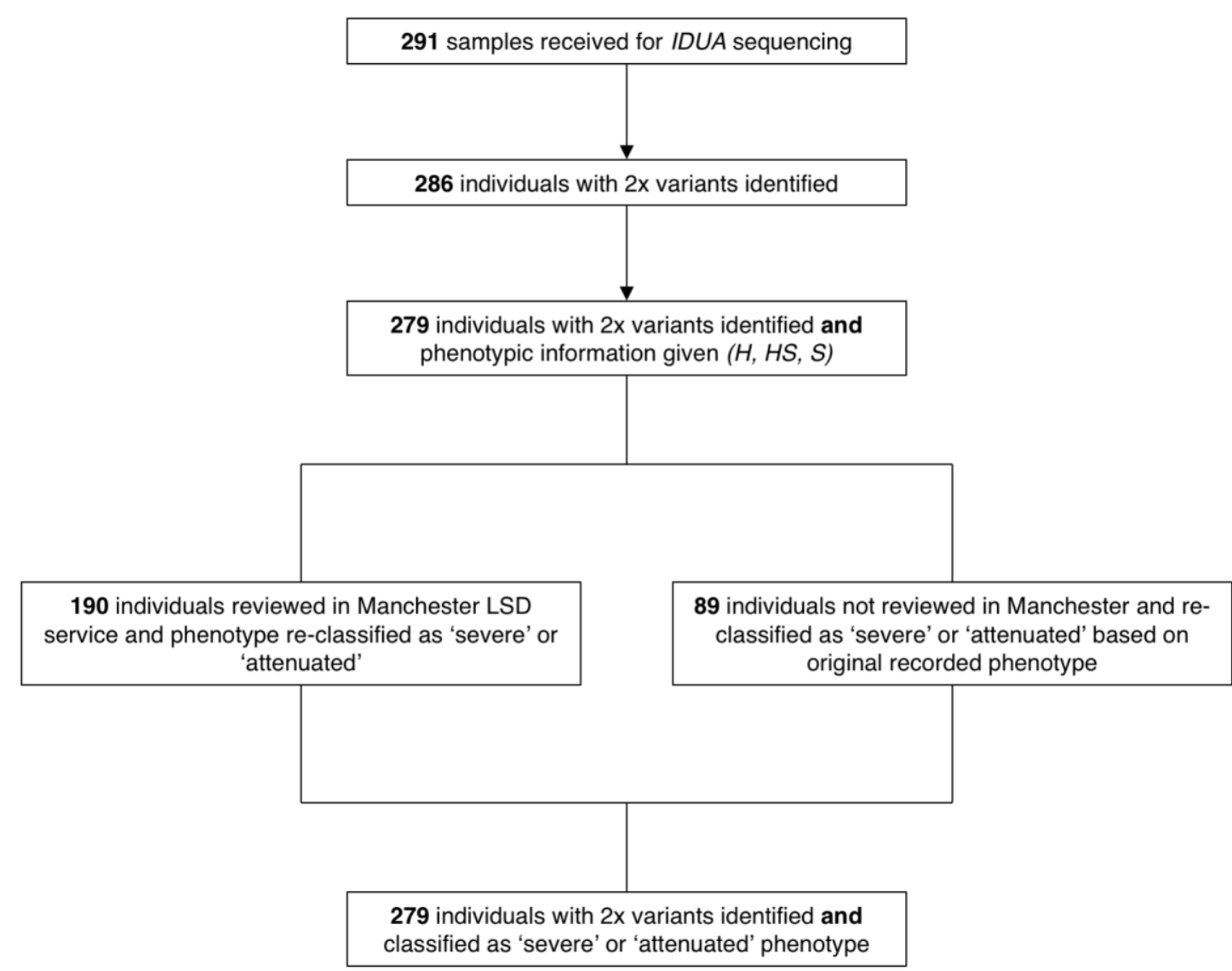

This article is protected by copyright. All rights reserved. 
Figure 2: 'Lollipop plot' visualization of IDUA variants identified in UK individuals using cBioPortal Mutation Mapper. (Excludes intronic variants, splice site variants and large deletions). Height corresponds to the number of times variant was observed in the cohort. The five most frequently observed variants are labelled.

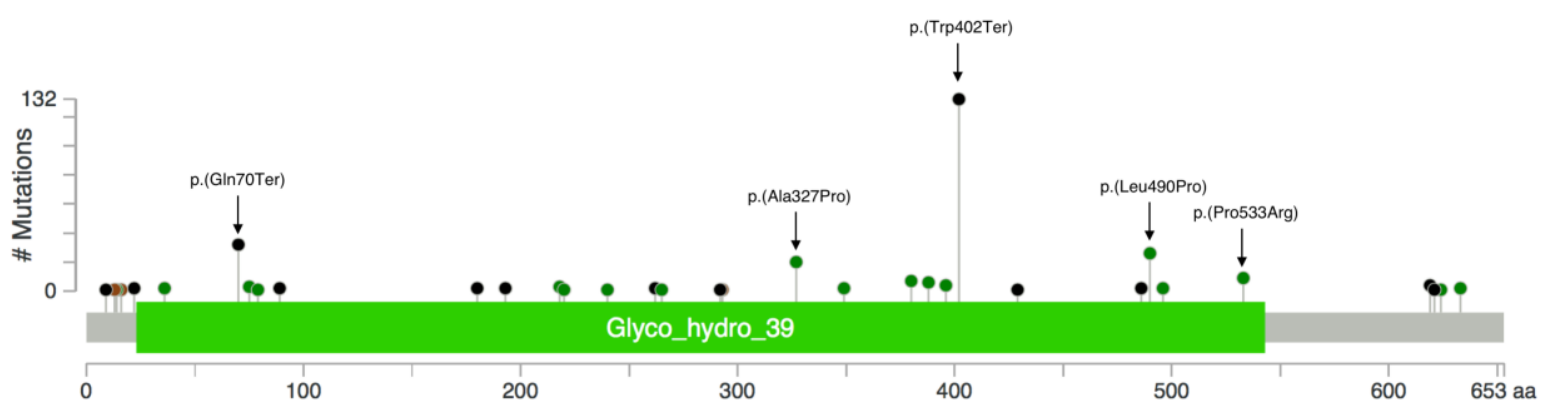

Missense variants

- Truncating variants (nonsense variants, frameshift deletions, duplications and insertions)

- In frame deletions, duplications and insertions

- Other (initiating codon changes) 
Figure 4: Process for developing genotype-phenotype relationships. *Treated as separate individuals if from different families, otherwise treated as single individual. Key - sev severe phenotype; att attenuated phenotypes; hom homozygous; comp het compound heterozygous

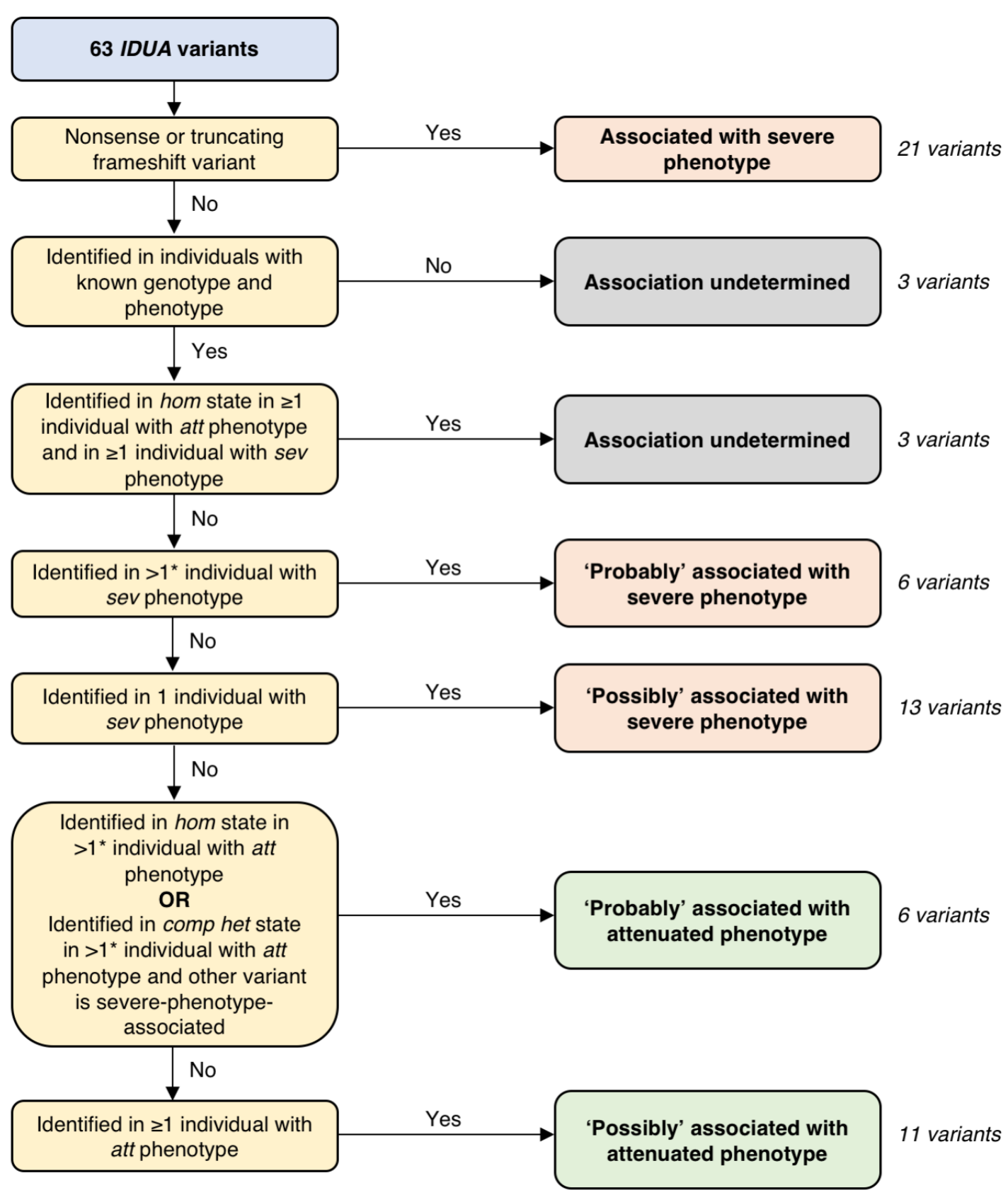

This article is protected by copyright. All rights reserved. 
Table 1: a) Geographical origin of samples received for IDUA sequencing and classification into phenotypic groups. In addition to UK and Ireland, samples were received from Pakistan, Kuwait, Saudi Arabia, Egypt, Jordan, Turkey, Denmark, India, Greece, Sweden, Italy, Russia and Latvia. b) Ethnic origin was confirmed for 131 individuals known to authors $S A J, J M, A G$.

Key: H, Hurler; HS, Hurler-Scheie; S, Scheie

\begin{tabular}{|c|c|c|c|c|}
\hline \multicolumn{5}{|l|}{ a) } \\
\hline $\begin{array}{l}\text { Phenotypic } \\
\text { group recorded } \\
\text { at time of } \\
\text { analysis (and } \\
\text { after re- } \\
\text { classification) }\end{array}$ & UK & Ireland & Other & Total \\
\hline $\begin{array}{l}\text { Hurler (\%) } \\
\text { ('severe- } \\
\text { phenotype') }\end{array}$ & $102(37 \%)$ & $78(28 \%)$ & $31(11 \%)$ & $211(76 \%)$ \\
\hline $\begin{array}{l}\text { Hurler-Scheie } \\
(\%)\end{array}$ & $34(12 \%)$ & $4(1 \%)$ & $20(7 \%)$ & $58(21 \%)$ \\
\hline Scheie (\%) & $9(3 \%)$ & 1 & 0 & $10(4 \%)$ \\
\hline $\begin{array}{l}\text { ('attenuated- } \\
\text { phenotype') }\end{array}$ & (43) (15\%) & (5) $(2 \%)$ & (20) (7\%) & (68) (24\%) \\
\hline Total & 145 & 83 & 51 & 279 \\
\hline \multicolumn{5}{|l|}{ b) } \\
\hline & \multicolumn{4}{|c|}{ Geographical origin of sample } \\
\hline Ethnic origin & UK & Ireland & Other & \\
\hline White British & $\begin{array}{l}75(51 \times H, \\
18 x H S, 6 x S)\end{array}$ & $1(H S)$ & - & \\
\hline Irish & - & $15(15 x H)$ & - & \\
\hline Pakistani & $13(2 x H, 11 x H S)$ & - & $4(4 x H S)$ & \\
\hline Indian & $1(H)$ & - & - & \\
\hline Saudi & 0 & - & $2(2 x H)$ & \\
\hline
\end{tabular}

This article is protected by copyright. All rights reserved. 


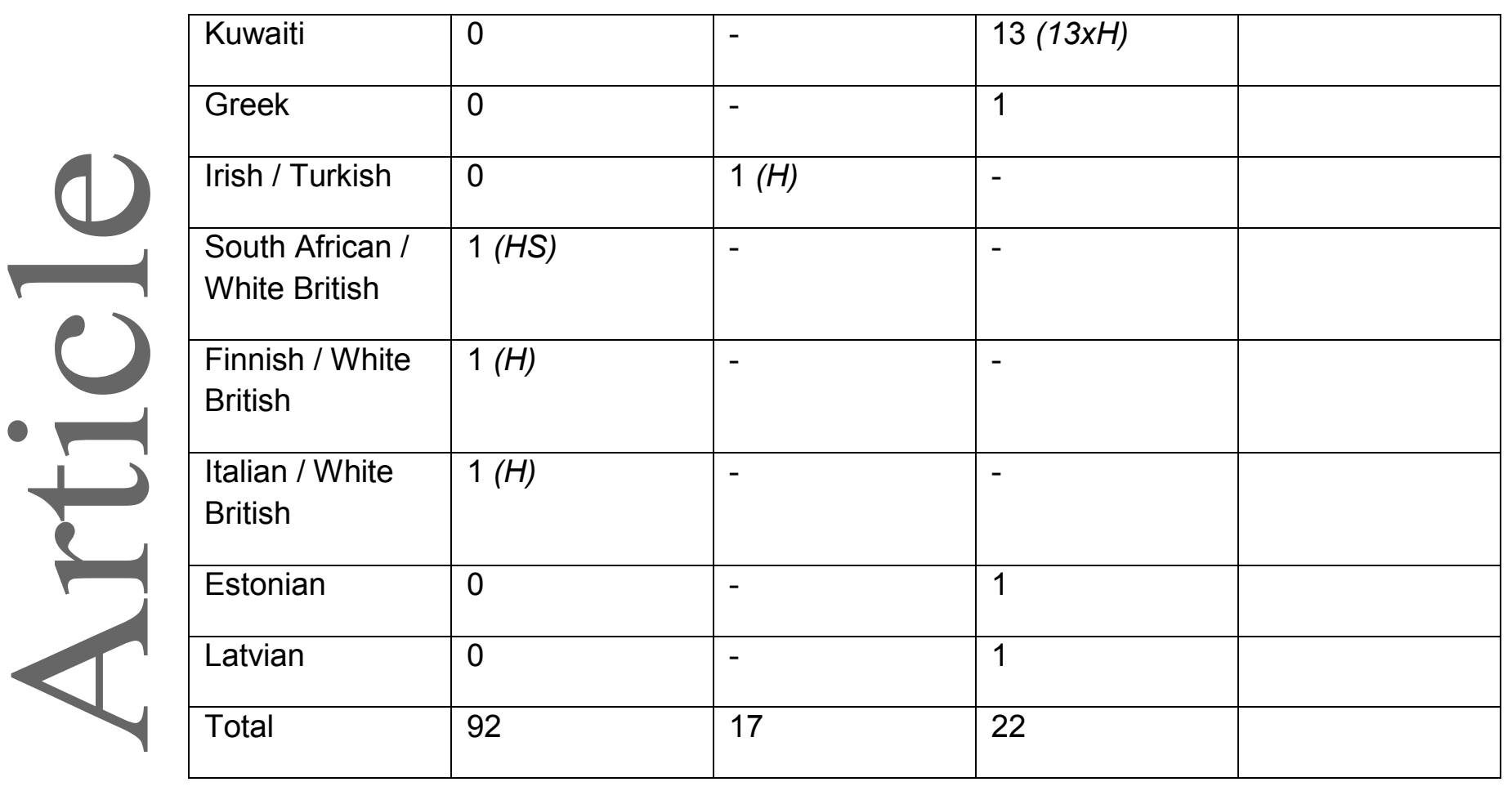

This article is protected by copyright. All rights reserved. 
Table 2: Novel IDUA variants identified in this cohort. Reference sequences used are NM_000203.3 and NG_008103.1 for non-coding variants. Variants were only observed in a single individual except c.386-1g>a which was observed in three individuals. For each individual, the second IDUA variant for that individual is given as well as iduronidase activity at diagnosis and clinical phenotype (where known). None of the variants were previously reported in literature and none were present in ExAC or HGMD. Mutation Taster predictions are not available for large deletions and intronic variants. SIFT, PolyPhen-2, FATHMM, KGGSeq and REVEL predictions are given for coding single nucleotide variants only. FATHMM-MKL scores are given for non-coding single nucleotide variants, expressed as $p$-values, where $p>0.5$ is predicted to be deleterious and $p<0.5$ is predicted to be neutral. REVEL scores range from $0-1$. Variants with values closer to 1 are more likely to be classed as pathogenic: sensitivity and specificity distribution for different REVEL score thresholds given in loannidis et al. (2016).

\begin{tabular}{|c|c|c|c|c|c|c|c|c|c|c|c|c|}
\hline DNA change & $\begin{array}{l}\text { Protein } \\
\text { change }\end{array}$ & $\begin{array}{l}\text { Varia } \\
\text { nt } \\
\text { type }\end{array}$ & $\begin{array}{l}\text { SIFT } \\
\text { predi } \\
\text { ction }\end{array}$ & $\begin{array}{l}\text { Mutatio } \\
\mathrm{n} \\
\text { Taster } \\
\text { predicti } \\
\text { on }\end{array}$ & $\begin{array}{l}\text { FATH } \\
\text { MM } \\
\text { predi } \\
\text { ction } \\
\text { (FAT } \\
\text { HMM } \\
\text {-MKL } \\
\text { score } \\
\text { ) }\end{array}$ & $\begin{array}{l}\text { Poly } \\
\text { Phen } \\
-2 \\
\text { predi } \\
\text { ction }\end{array}$ & $\begin{array}{l}\text { KGG } \\
\text { seq } \\
\text { predi } \\
\text { ction }\end{array}$ & $\begin{array}{l}\text { RE } \\
\text { VE } \\
\text { L } \\
\text { sco } \\
\text { re }\end{array}$ & $\begin{array}{l}\text { Variant on opposite } \\
\text { chromosome }\end{array}$ & $\begin{array}{l}\text { Iduro } \\
\text { nidas } \\
\text { e } \\
\text { activit } \\
\text { y } \\
\text { (umol/ } \\
\text { g.hr) } \\
(10- \\
50)\end{array}$ & $\begin{array}{l}\text { Phenot } \\
\text { ype }\end{array}$ & $\begin{array}{l}\text { Variant } \\
\text { interpreta } \\
\text { tion } \\
\text { (criteria } \\
\text { met) }\end{array}$ \\
\hline c. $1 A>G$ & p.(Met1?) & $\begin{array}{l}\text { Initiati } \\
\text { ng } \\
\text { codon } \\
\text { chang }\end{array}$ & & $\begin{array}{l}\text { Diseas } \\
\text { e } \\
\text { causin }\end{array}$ & & & & & $\begin{array}{l}\text { c.1A>G } \\
\text { [p.(Met1?)] }\end{array}$ & - & $\begin{array}{l}\text { Severe } \\
(\mathrm{H})\end{array}$ & $\begin{array}{l}P \\
\text { at } \\
\text { ho } \\
\text { ge }\end{array}$ \\
\hline
\end{tabular}

This article has been accepted for publication and undergone full peer review but has not been through the copyediting, typesetting, pagination and proofreading process, which may lead to differences between this version and the Version of Record. Please cite this article as doi: 10.1002/humu.23301.

This article is protected by copyright. All rights reserved. 


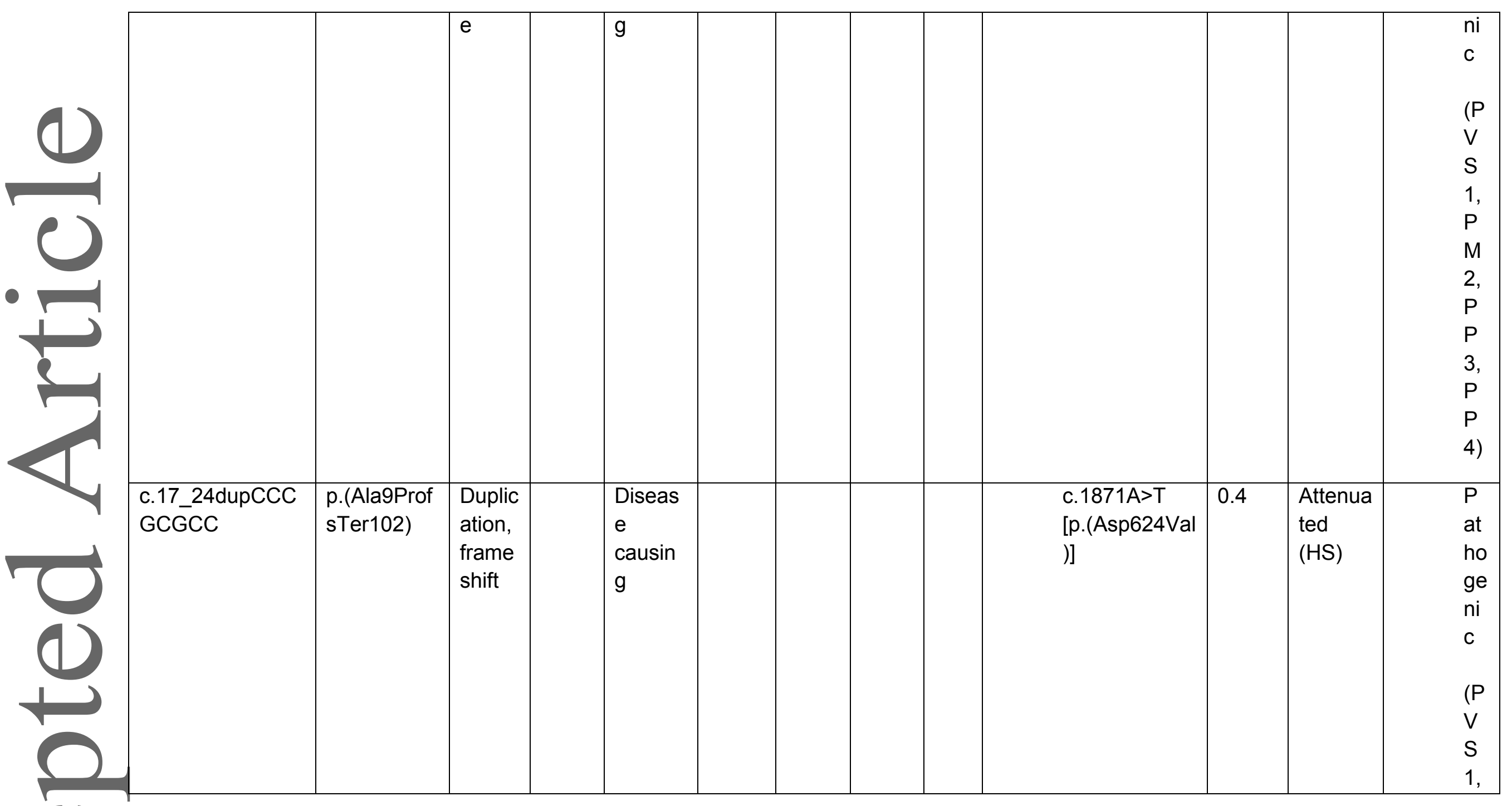

This article is protected by copyright. All rights reserved.

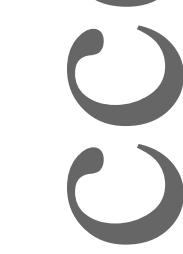




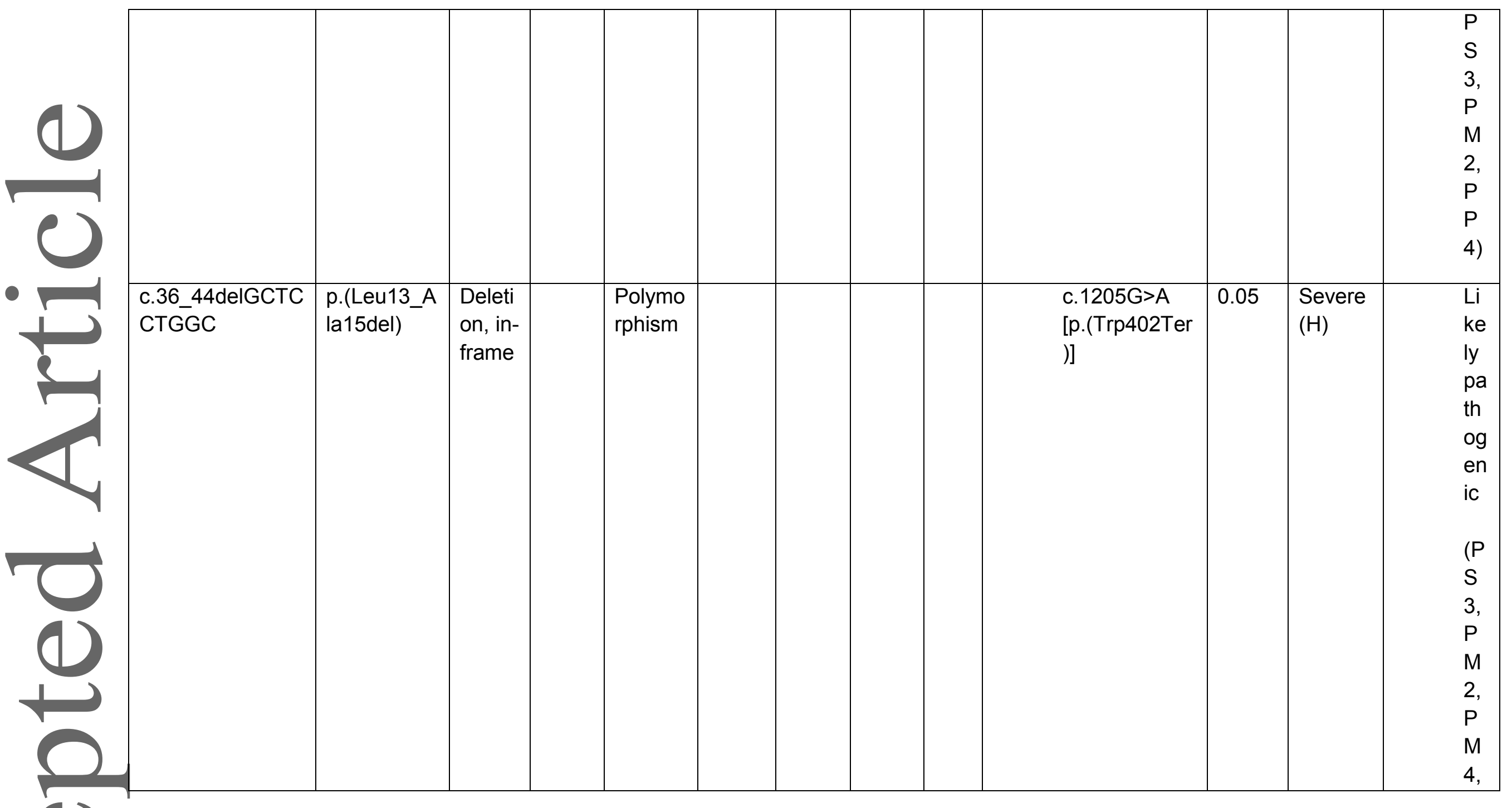

This article is protected by copyright. All rights reserved. 


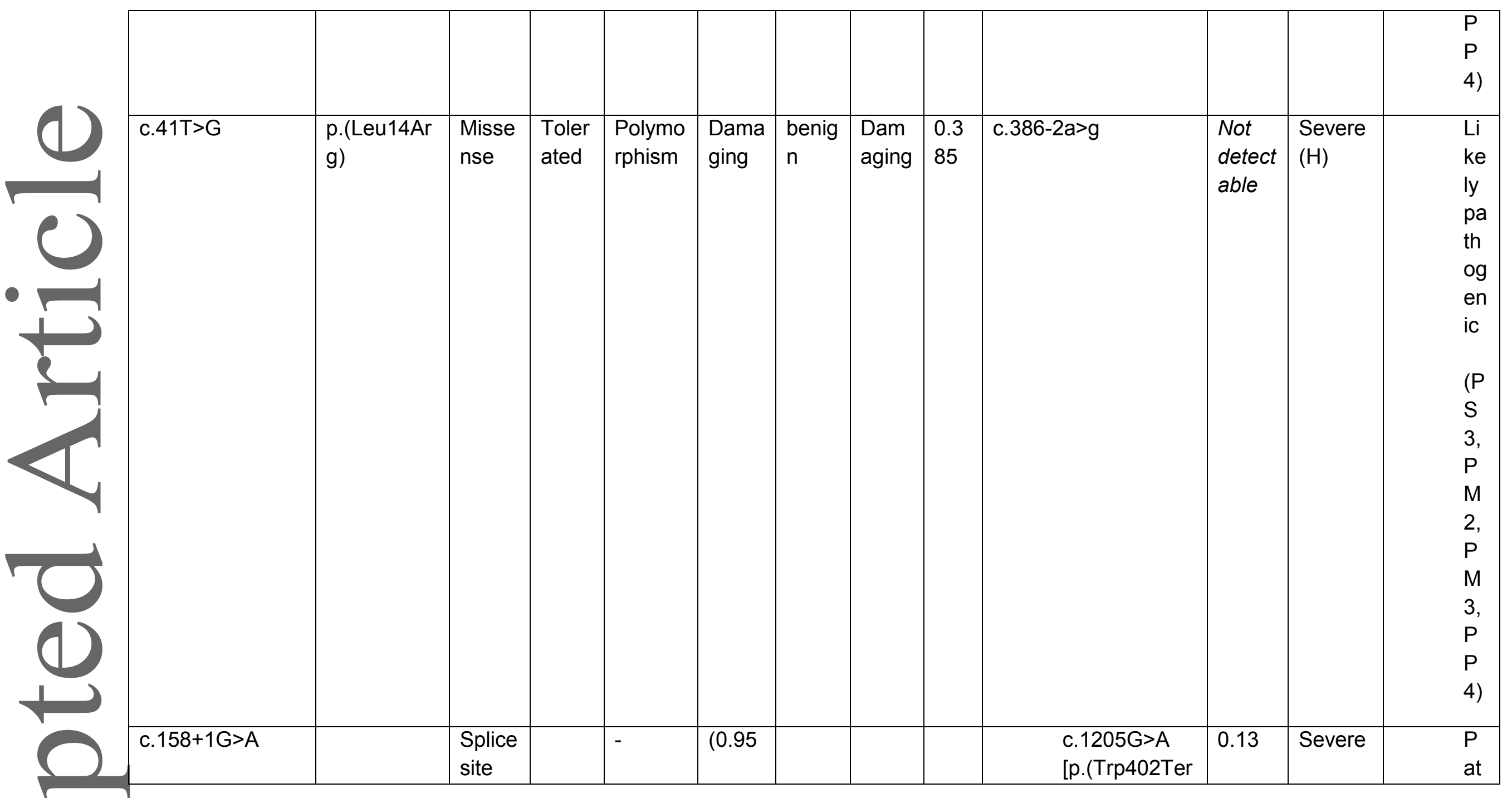

This article is protected by copyright. All rights reserved.

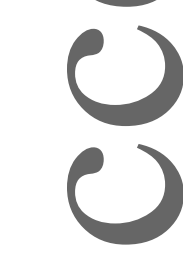




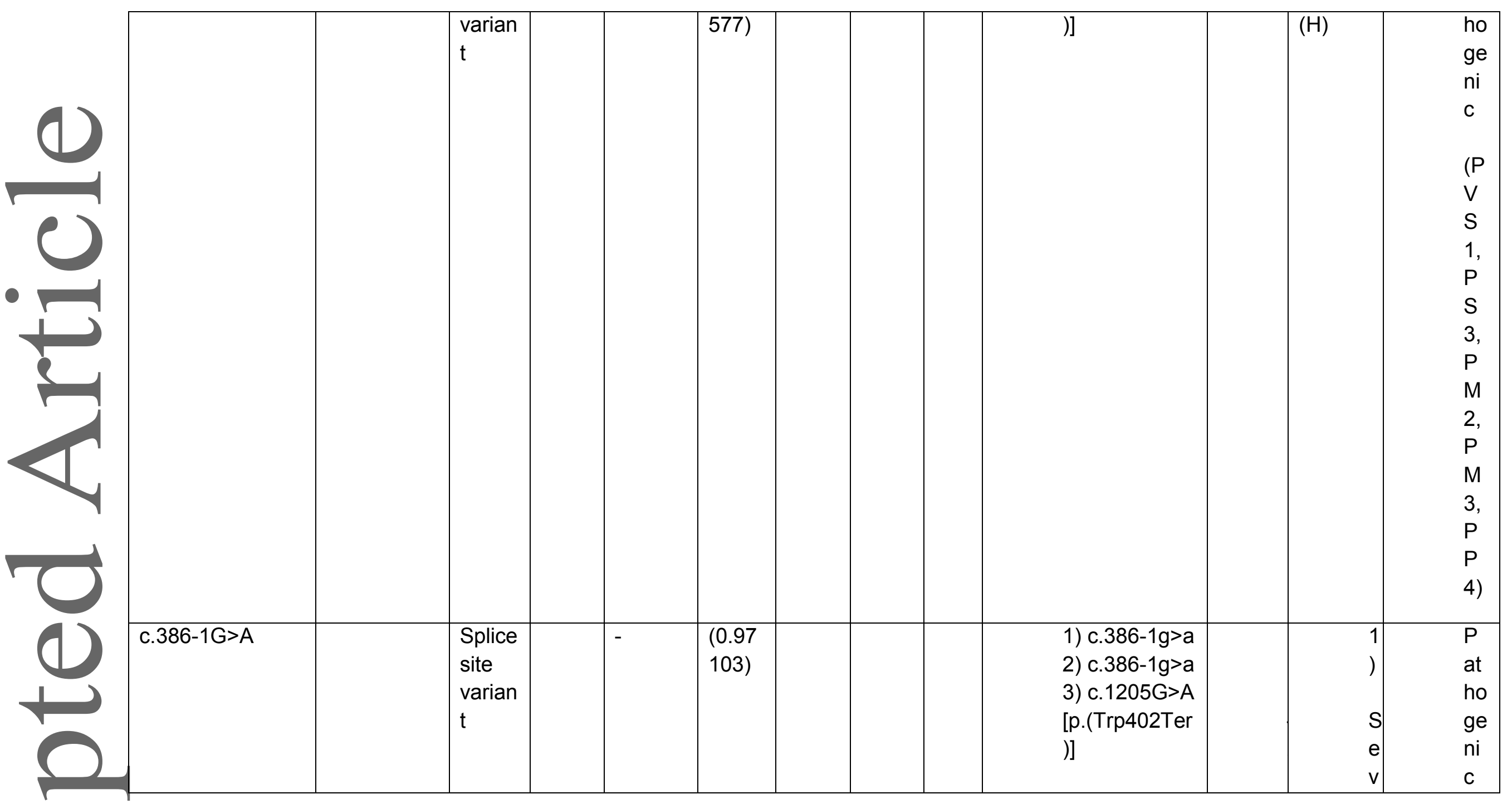

This article is protected by copyright. All rights reserved.

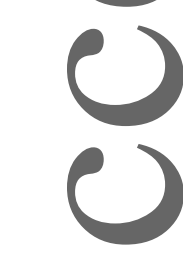




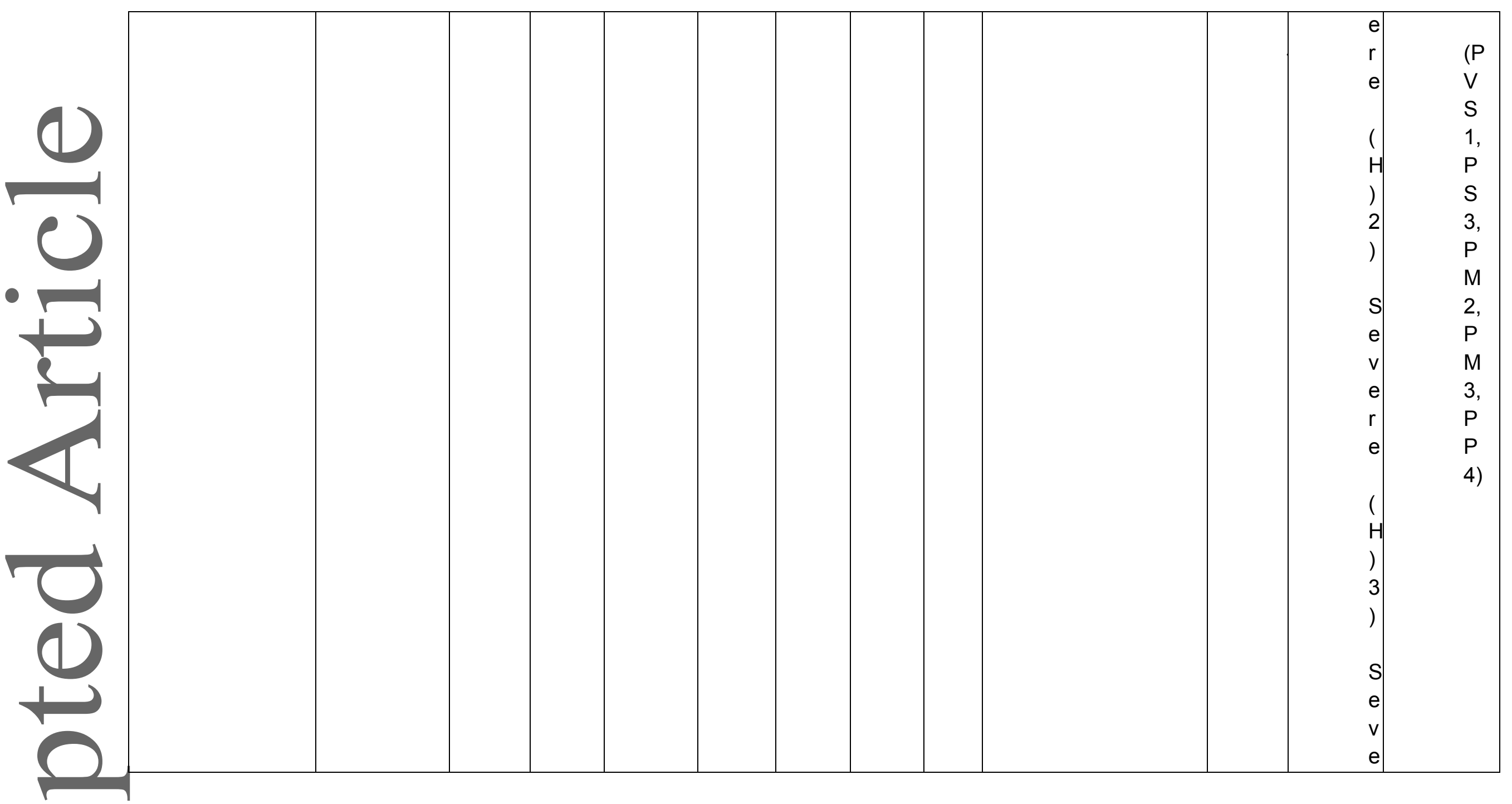

This article is protected by copyright. All rights reserved.

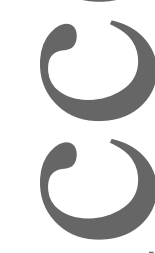




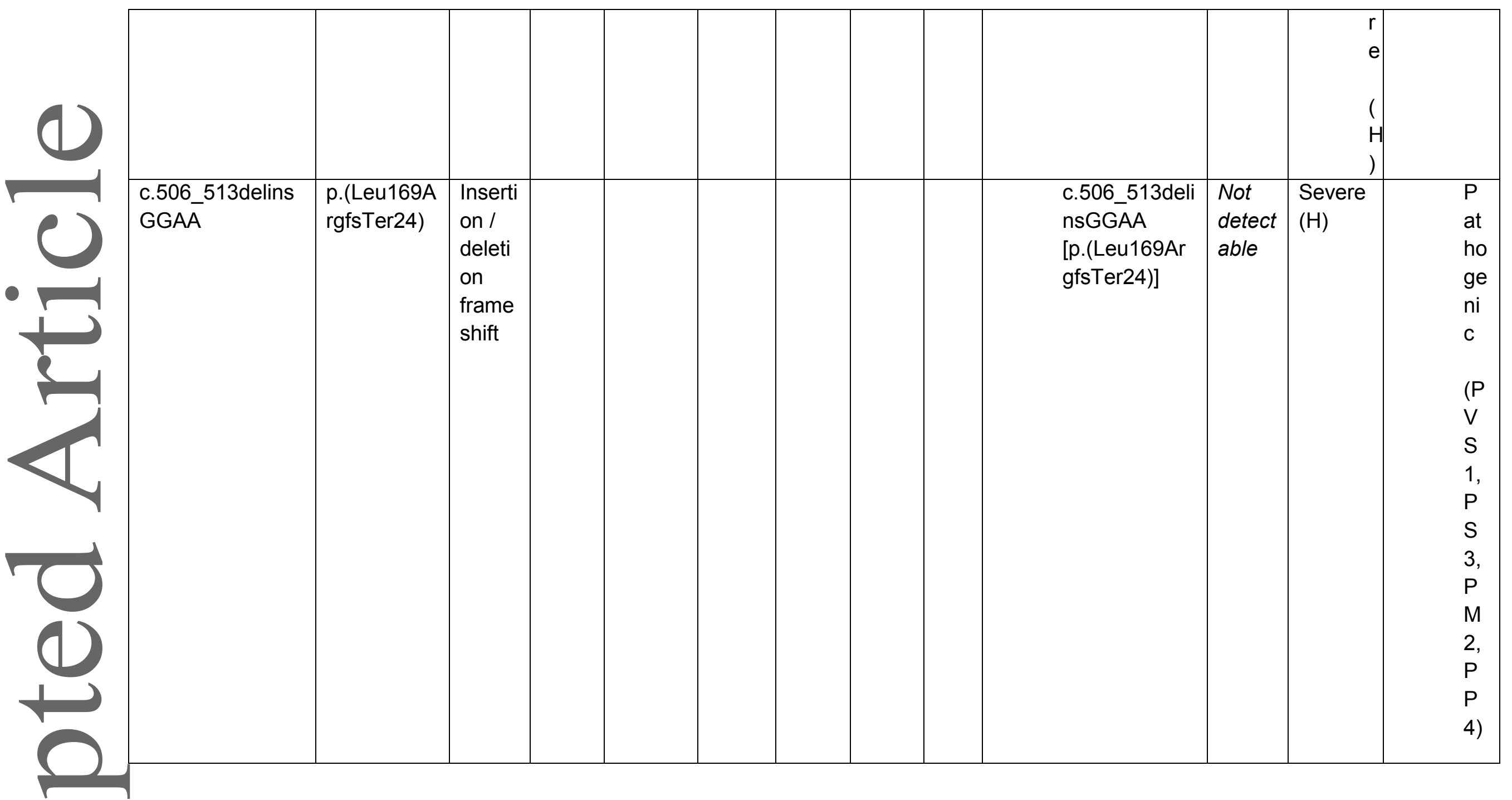

This article is protected by copyright. All rights reserved. 


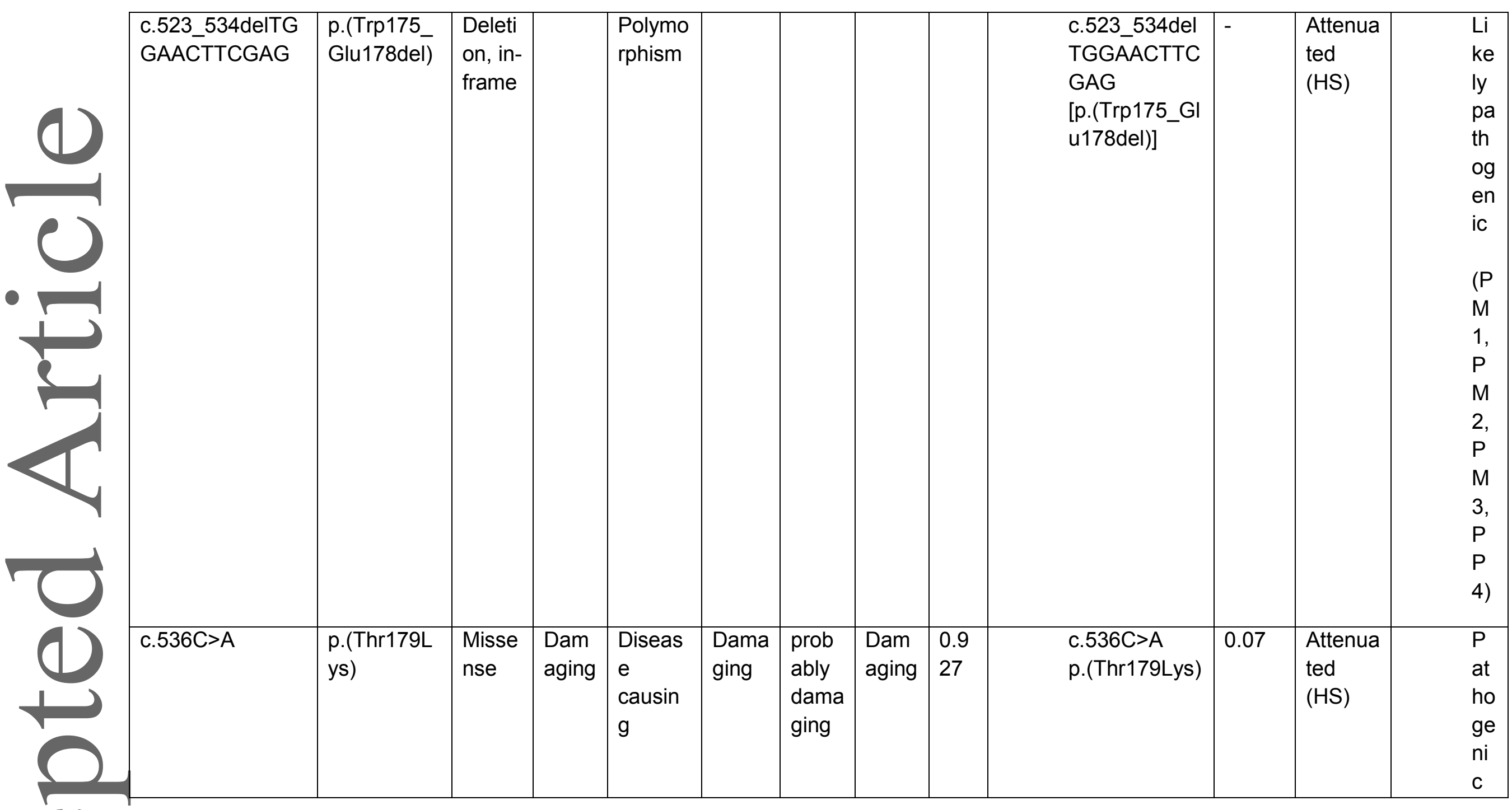

This article is protected by copyright. All rights reserved. 


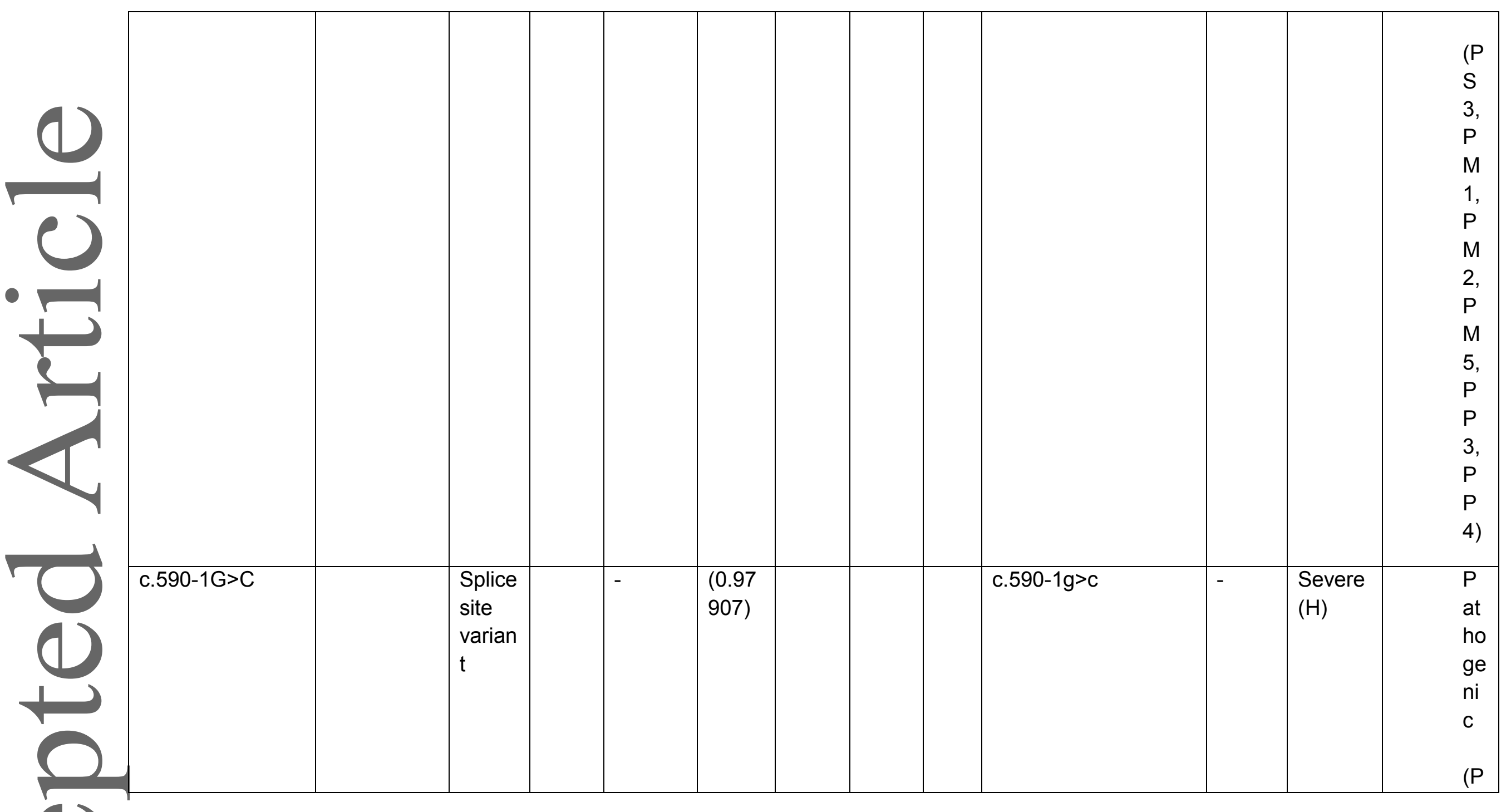

This article is protected by copyright. All rights reserved.

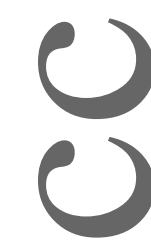




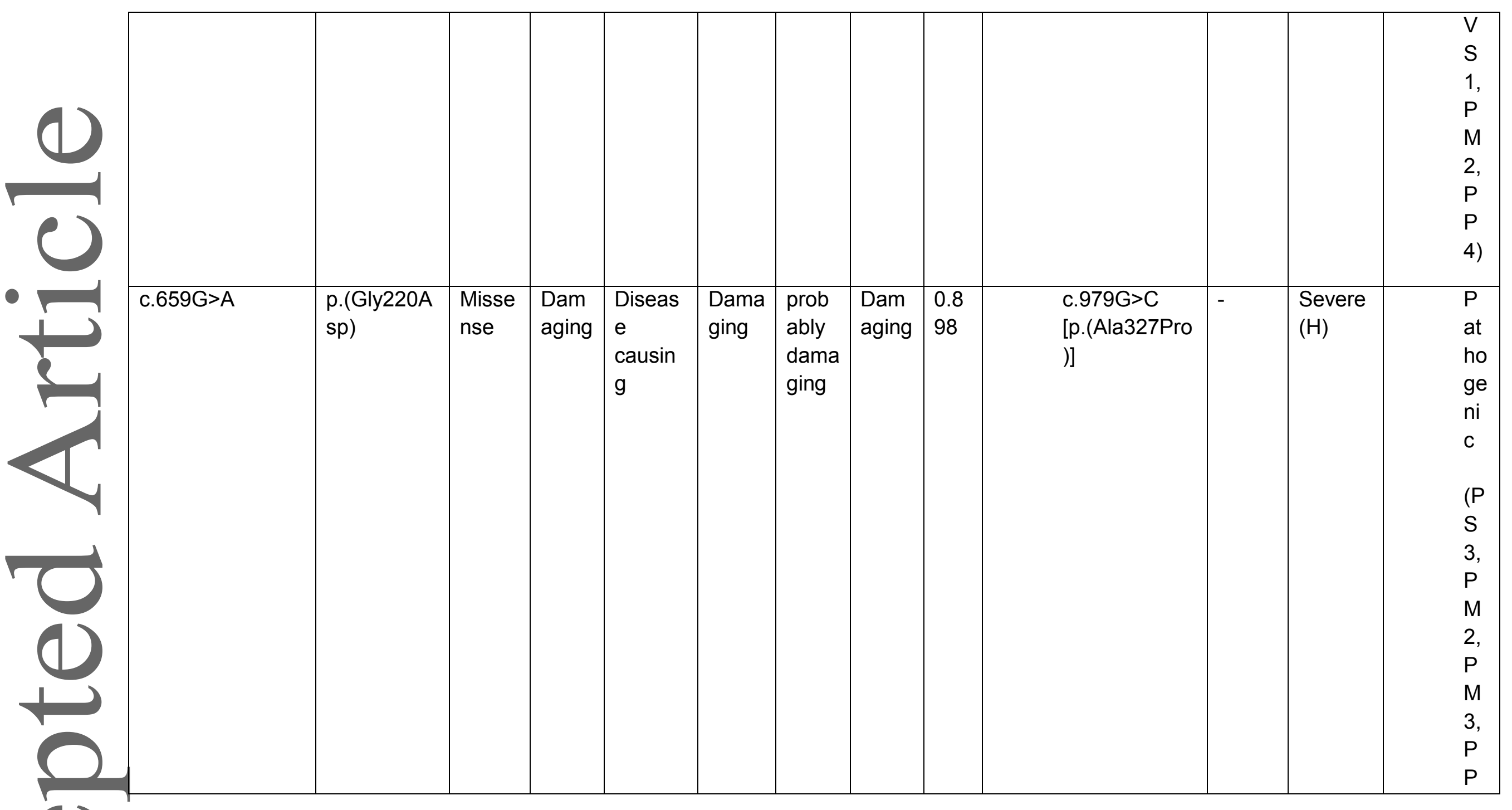

This article is protected by copyright. All rights reserved. 


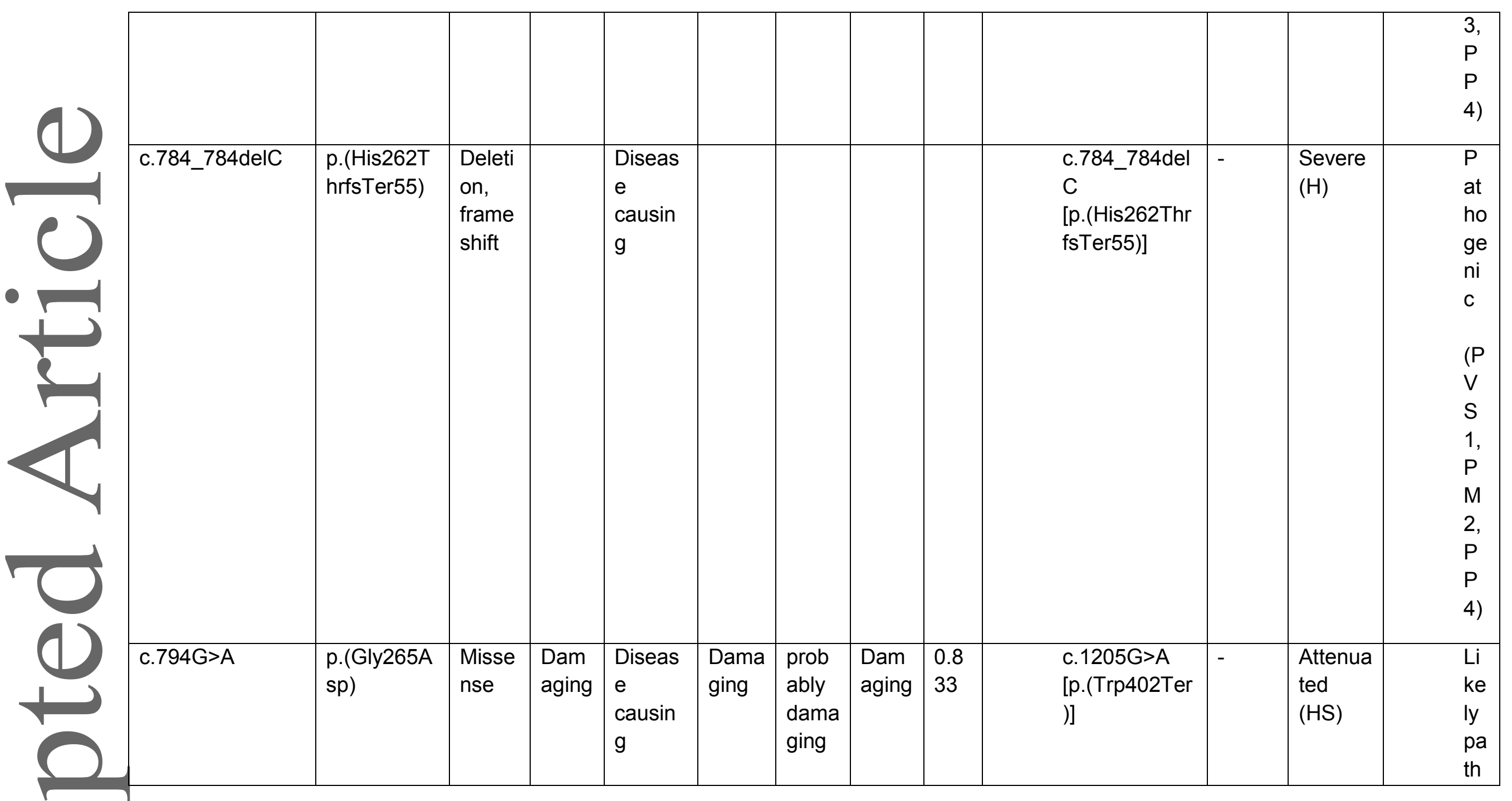

This article is protected by copyright. All rights reserved. 


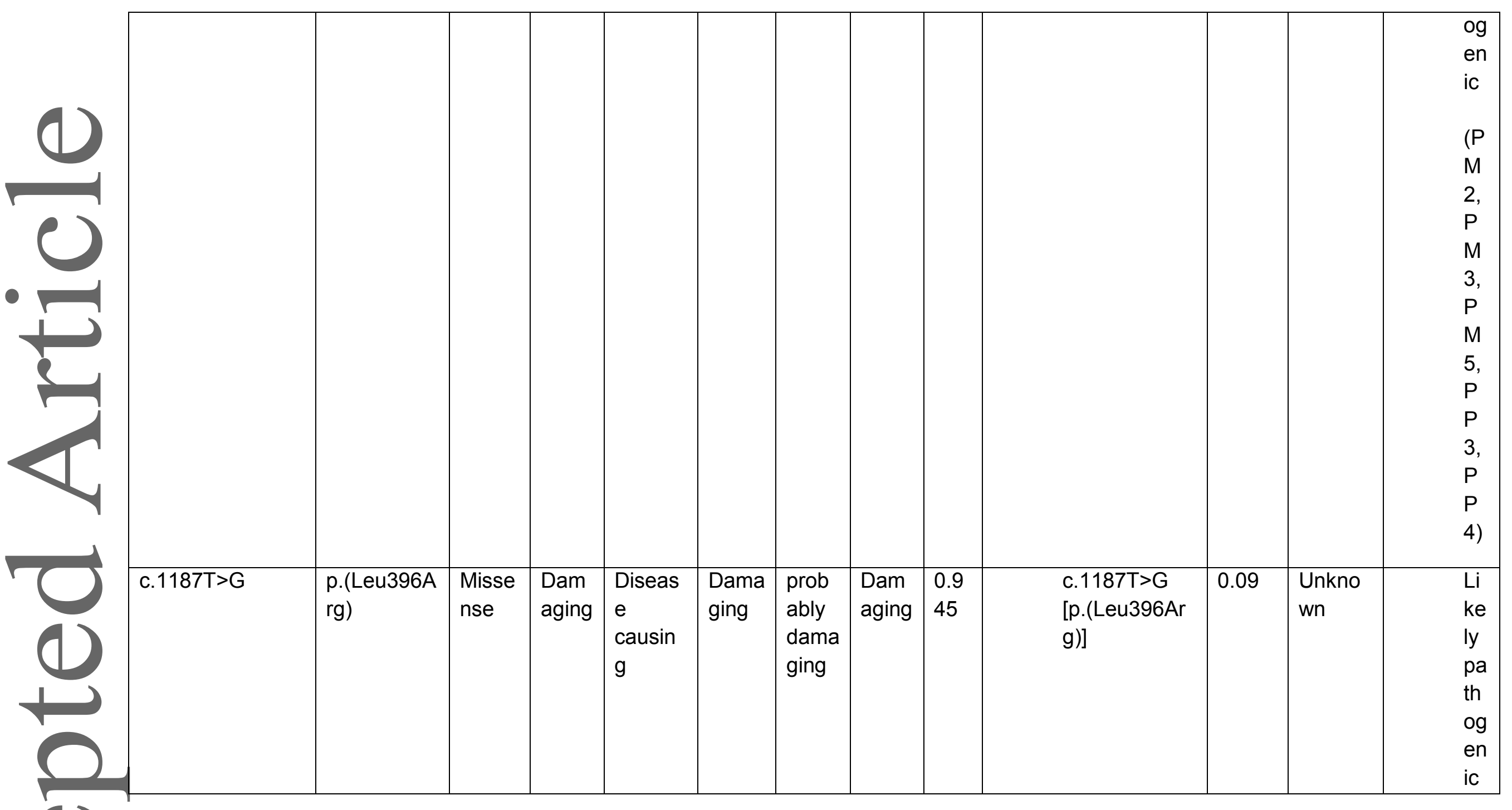

This article is protected by copyright. All rights reserved. 


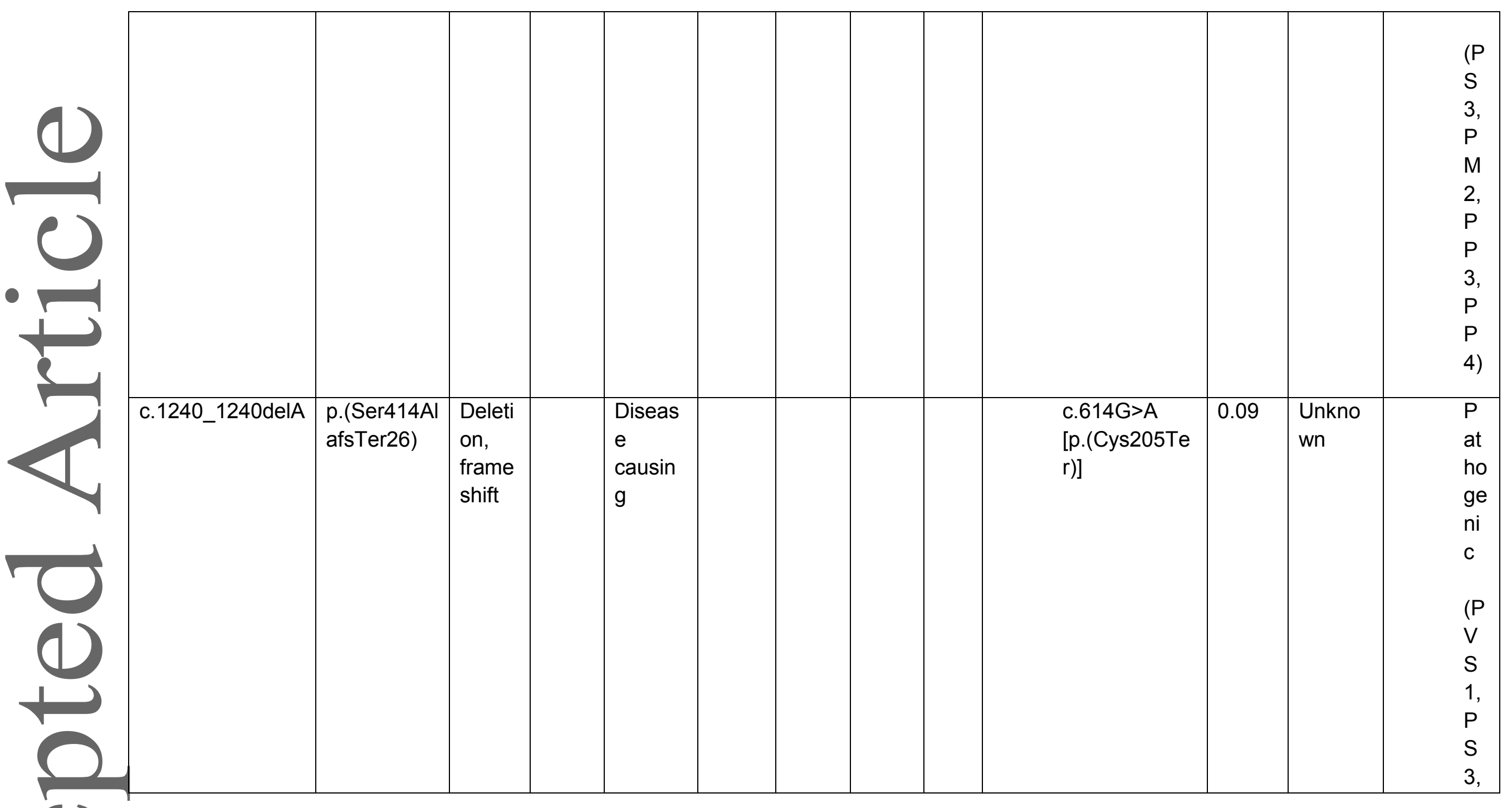

This article is protected by copyright. All rights reserved. 


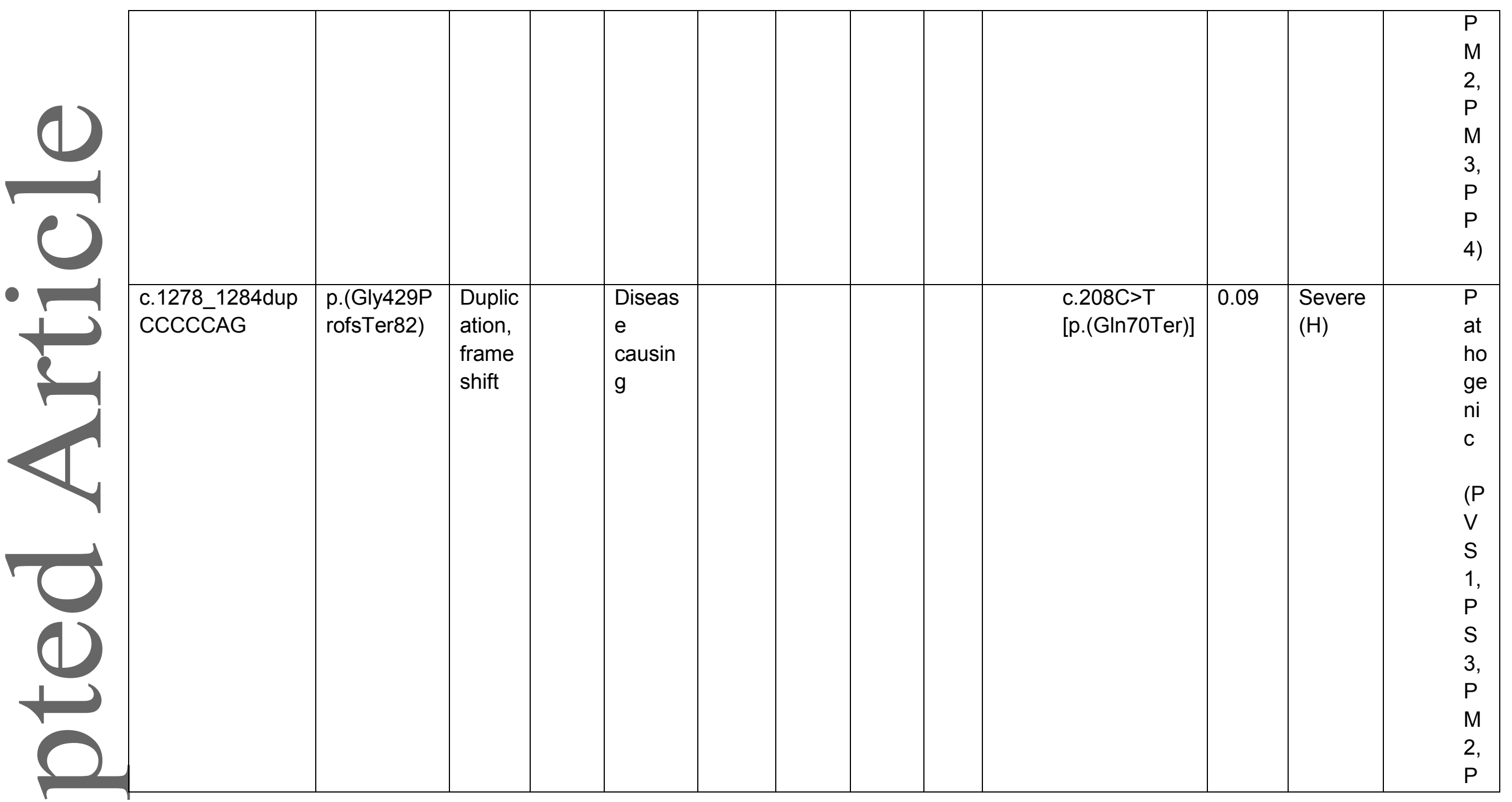

This article is protected by copyright. All rights reserved.

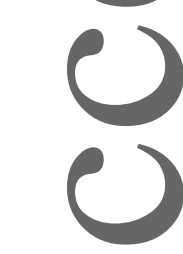




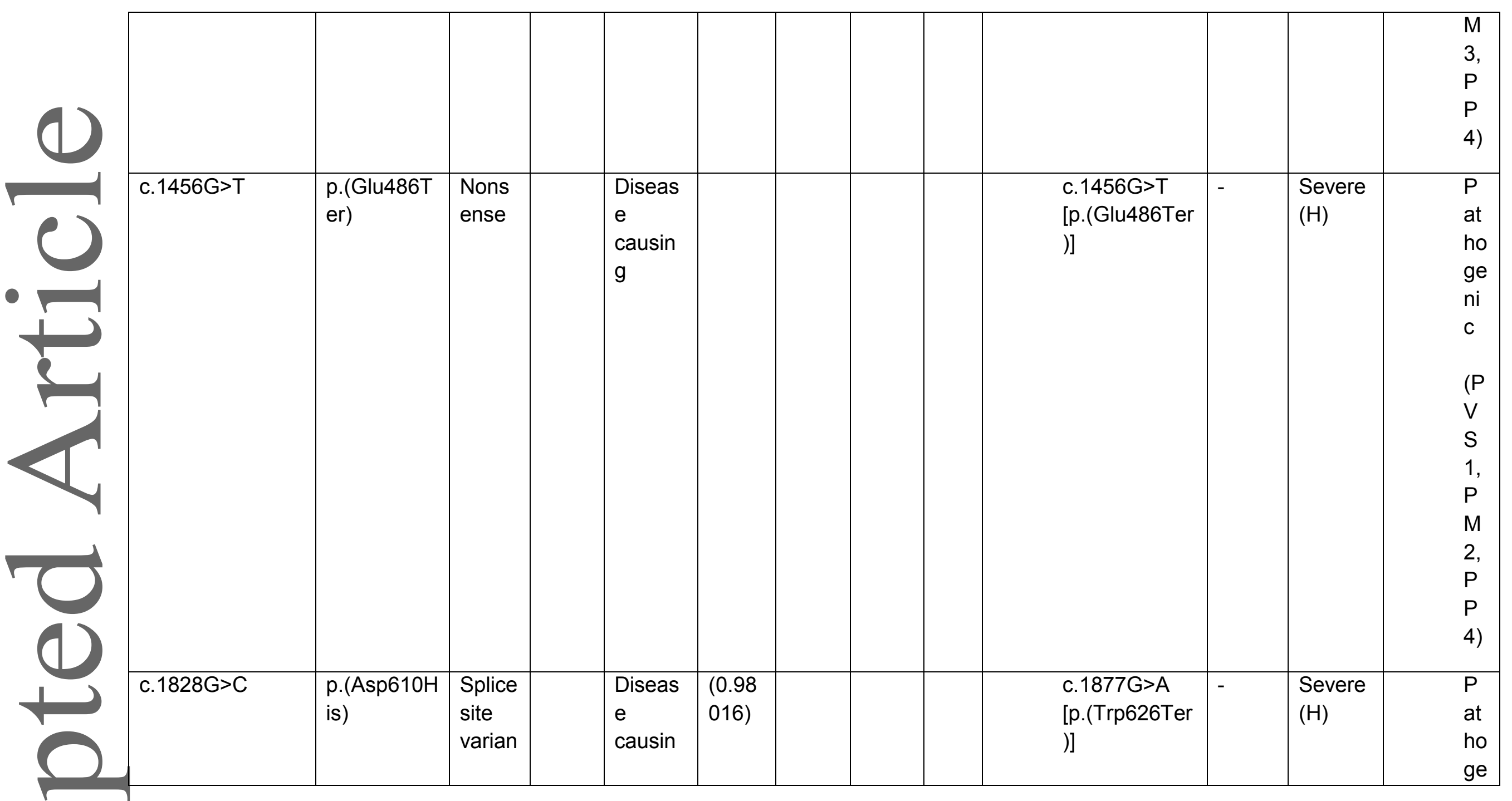

This article is protected by copyright. All rights reserved. 


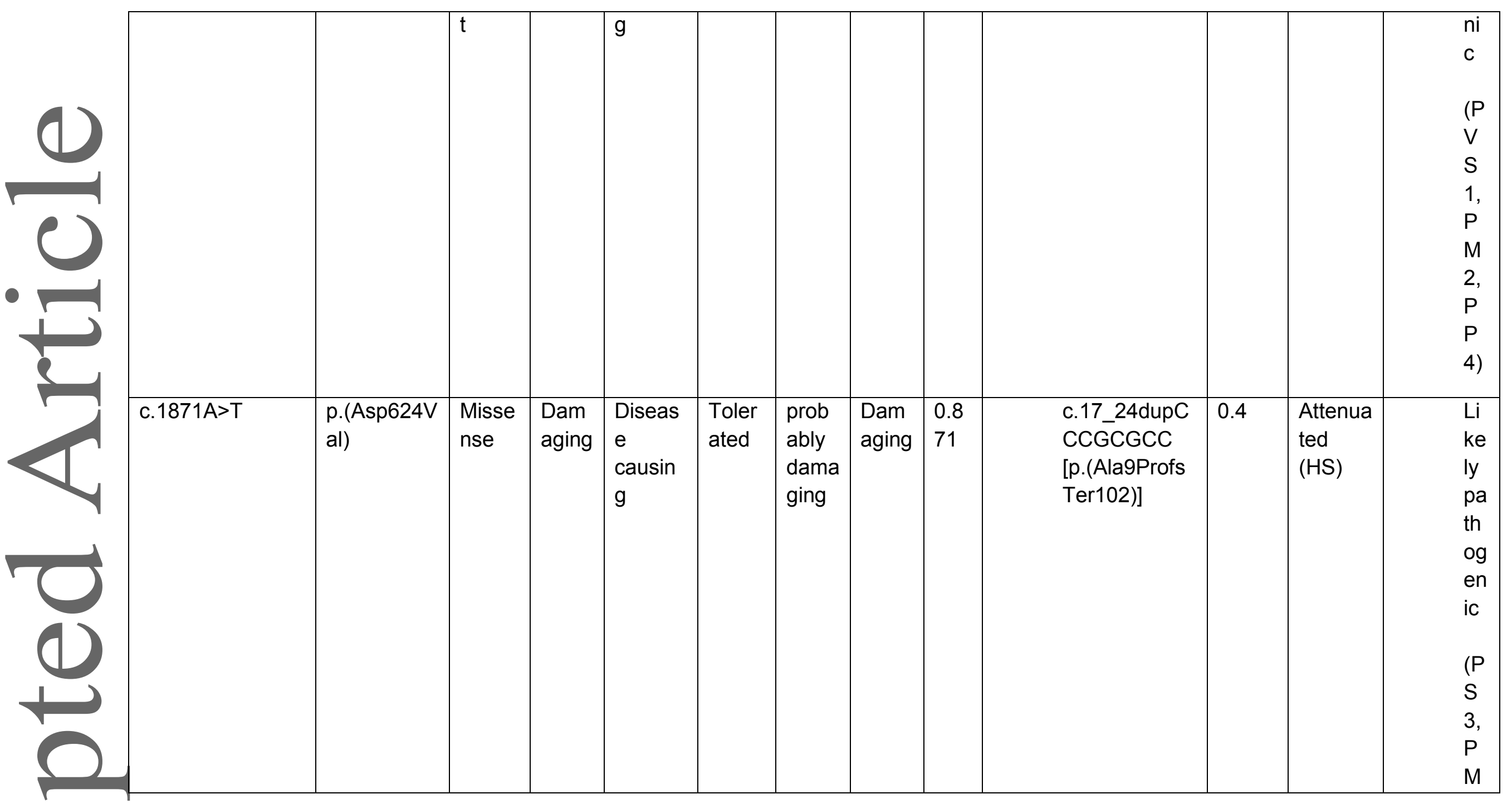

This article is protected by copyright. All rights reserved. 


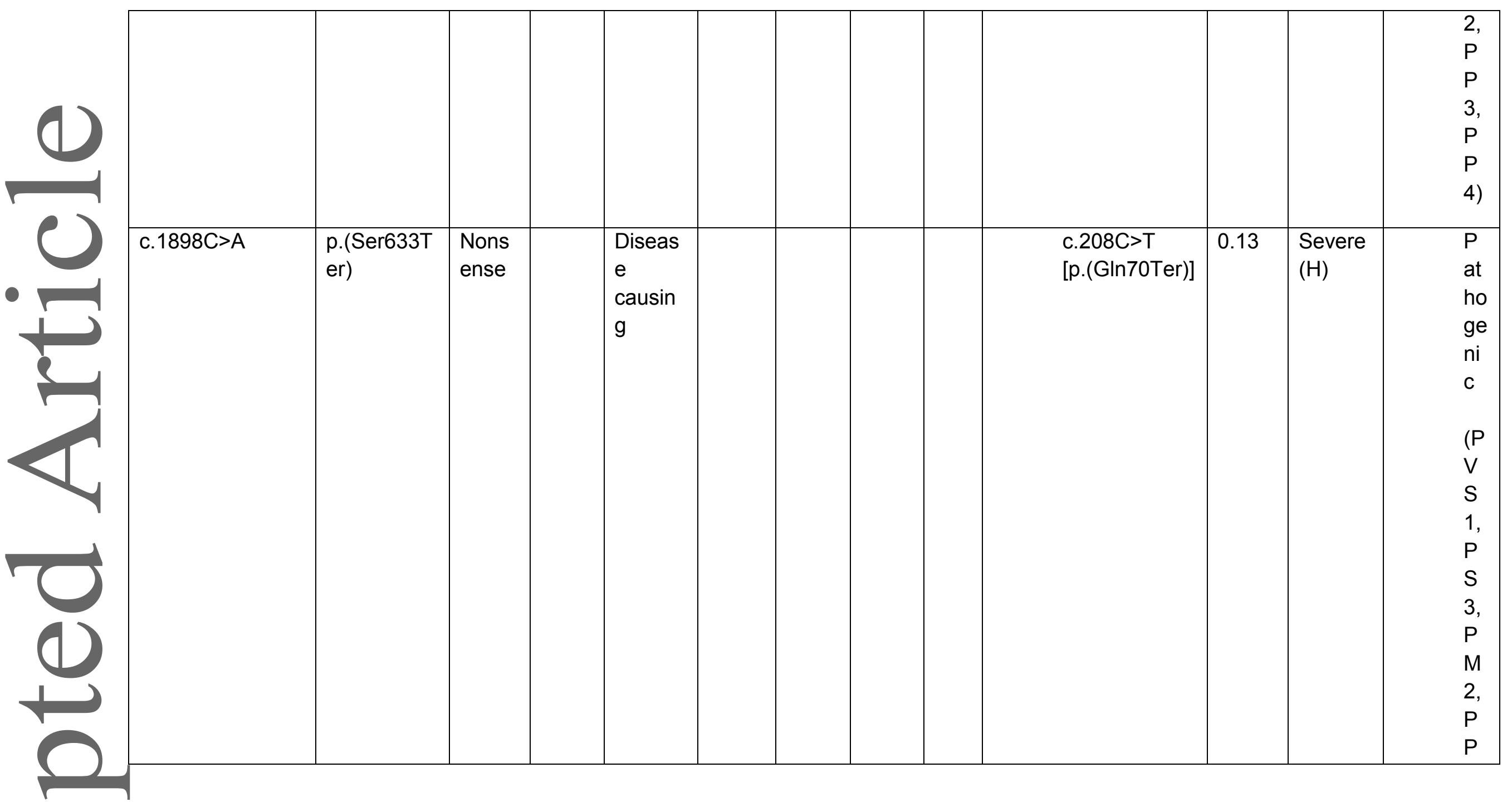

This article is protected by copyright. All rights reserved. 


\begin{tabular}{|l|l|l|l|l|l|l|l|l|l|l|l|}
\hline & & & & & & & & & & & \\
\hline
\end{tabular}

Key - UK, United Kingdom; Ire, Ireland; Oth, Other regions; sev, severe phenotype; att, attenuated phenotype; unk, unknown phenotype; AA, amino acid;

FATHMM, Functional Analysis Through Hidden Markov Models; MKL, multiple kernel learning; KGGSeq, Knowledge-based mining platform for Genomic and

Genetic studies using Sequence data; REVEL, rare exome variant ensemble learner, ExAC, Exome Aggregation Consortium. PVS, PS, PM and PP refer to very strong, strong, moderate and supporting criteria for classifying pathogenic variants as described by Richards et al. (2015).

This article is protected by copyright. All rights reserved. 
Table 3: Most frequently observed genotypes in UK cohort. Total of 145 individuals with both IDUA variants identified in UK cohort, 102 with severe phenotypes and 41 with attenuated phenotypes (34 Hurler-Scheie, 9 Scheie). Reference sequences used are NM_000203.3 and NG_008103.1 for non-coding variants. H, Hurler; HS, Hurler-Scheie; S, Scheie.

\begin{tabular}{|c|c|c|c|}
\hline \multirow{2}{*}{$\begin{array}{l}\text { Ran } \\
\mathrm{k}\end{array}$} & Severe & \multicolumn{2}{|l|}{ Attenuated } \\
\hline & $(\mathrm{H})$ & (HS) & (S) \\
\hline 1 & $\begin{array}{l}\text { c. } 1205 G>A / \\
\text { c. } 1205 G>A \\
\text { [p.(Trp402Te } \\
\text { r) / } \\
\text { p.(Trp402Ter } \\
\text { )] } \\
\text { (30 } \\
\text { individuals) }\end{array}$ & $\begin{array}{l}\text { c.1469T>C / } \\
\text { c.1469T>C } \\
\text { [p.(Leu490Pr } \\
\text { o) / } \\
\text { p.(Leu490Pro } \\
\text { ]] } \\
\text { (13 } \\
\text { individuals) }\end{array}$ & $\begin{array}{l}\text { c. } 1205 \mathrm{G}>\mathrm{A}[\mathrm{p} .(\text { Trp402Ter })] / \\
\text { c. } 590-7 \mathrm{~g}>\mathrm{a} \\
\text { ( } 7 \text { individuals) }\end{array}$ \\
\hline 2 & $\begin{array}{l}\text { c. } 1205 \mathrm{G}>\mathrm{A} / \\
\text { c. } 208 \mathrm{C}>\mathrm{T} \\
{[\mathrm{p} .(\mathrm{Trp} 402 \mathrm{Te}} \\
\text { r) / } \\
\text { p.(GIn70Ter)] } \\
\text { (19 } \\
\text { individuals) }\end{array}$ & $\begin{array}{l}\text { c. } 1598 C>\mathrm{G} / \\
\text { c. } 1598 \mathrm{C}>\mathrm{G} \\
\text { [p.(Pro533Arg } \\
\text { )/ } \\
\text { p.(Pro533Arg } \\
\text { )] } \\
\text { (3 individuals) }\end{array}$ & $\begin{array}{l}\text { c.576dupC / } \\
\text { c.878_889dupCCCCCATTTA } \\
\text { CA } \\
\text { p.(Met193HisfsTer206) / } \\
\text { p.(Thr293_Tyr296dup) } \\
\text { (1 individual) }\end{array}$ \\
\hline 3 & $\begin{array}{l}\text { c. } 1205 \mathrm{G}>\mathrm{A} / \\
\text { c. } 979 \mathrm{G}>\mathrm{C} \\
\text { [p. }(\text { Trp402Te } \\
\text { r) / } \\
\text { p.(Ala327Pro } \\
\text { )] } \\
\text { (12 } \\
\text { individuals) }\end{array}$ & $\begin{array}{l}\text { c. } 1205 G>A / \\
\text { c. } 1139 A>G \\
\text { [p. }(\text { Trp402Ter } \\
) / \\
\text { p.(GIn380Arg } \\
)] \\
\text { (3 individuals) }\end{array}$ & $\begin{array}{l}\text { c. } 208 \mathrm{C}>\mathrm{T}[\mathrm{p} .(\mathrm{G} \ln 70 T e r)] / \\
\text { c.590-7G>A } \\
\text { (1 individual) }\end{array}$ \\
\hline
\end{tabular}

This article has been accepted for publication and undergone full peer review but has not been through the copyediting, typesetting, pagination and proofreading process, which may lead to differences between this version and the Version of Record. Please cite this article as doi: 10.1002/humu.23301.

This article is protected by copyright. All rights reserved. 
Table 4: Genotype-phenotype relationships based on observations in this cohort. Associations with phenotype were made for variants identified in 279 individuals with known genotype and phenotype. The combination of two severe-phenotype-associated variants is predicted to result in a severe phenotype. One or more attenuated-phenotype-associated variants are predicted to result in attenuated phenotypes. Reference sequences used are NM_000203.3 and NG_008103.1 for noncoding variants.

\begin{tabular}{|c|c|c|c|}
\hline & Associated with seve & phenotype & Associated with attenuated phenotypes \\
\hline \multirow{13}{*}{$\begin{array}{l}\text { Nonse } \\
\text { nse or } \\
\text { truncati } \\
\text { ng } \\
\text { frames } \\
\text { hift } \\
\text { variant } \\
\text { s }\end{array}$} & $\begin{array}{l}\text { c.17_24dupCCCGC } \\
\text { GCC }\end{array}$ & $\begin{array}{l}\text { p.(Ala9ProfsTer } \\
\text { 102) }\end{array}$ & \\
\hline & c.65_65delC & $\begin{array}{l}\text { p.(Pro22ArgfsT } \\
\text { er86) }\end{array}$ & \\
\hline & c. $192 C>A$ & p.(Tyr64Ter) & \\
\hline & c. $208 \mathrm{C}>\mathrm{T}$ & p.(GIn70Ter) & \\
\hline & $\begin{array}{l}\text { c.506_513delinsGG } \\
\text { AA }\end{array}$ & $\begin{array}{l}\text { p.(Leu169Argfs } \\
\text { Ter24) }\end{array}$ & \\
\hline & $\begin{array}{l}\text { c.540_544delGAAT } \\
\text { G }\end{array}$ & p.(Trp180Ter) & \\
\hline & c.576dupC & $\begin{array}{l}\text { p.(Met193Hisfs } \\
\text { Ter206) }\end{array}$ & \\
\hline & c. $606 \mathrm{C}>\mathrm{A}$ & p.(Tyr202Ter) & \\
\hline & $\begin{array}{l}\text { c.613_617dupTGCT } \\
\text { c }\end{array}$ & $\begin{array}{l}\text { p.(Glu207Alafs } \\
\text { Ter29) }\end{array}$ & \\
\hline & c.784_784delC & $\begin{array}{l}\text { p.(His262Thrfs } \\
\text { Ter55) }\end{array}$ & \\
\hline & c.876_876delC & $\begin{array}{l}\text { p.(Asp292Glufs } \\
\text { Ter25) }\end{array}$ & \\
\hline & c.895G $>\mathrm{T}$ & p.(Glu299Ter) & \\
\hline & c. $1205 \mathrm{G}>\mathrm{A}$ & p.(Trp402Ter) & \\
\hline
\end{tabular}

This article is protected by copyright. All rights reserved. 


\begin{tabular}{|c|c|c|c|c|}
\hline & c.1240_1240delA & $\begin{array}{l}\text { p.(Ser414Alafs } \\
\text { Ter26) }\end{array}$ & & \\
\hline & $\begin{array}{l}\text { c.1278_1284dupCC } \\
\text { CCCAG }\end{array}$ & $\begin{array}{l}\text { p.(Gly429Profs } \\
\text { Ter82) }\end{array}$ & & \\
\hline & c. $1456 \mathrm{G}>\mathrm{T}$ & p.(Glu486Ter) & & \\
\hline & c. $1855 \mathrm{C}>\mathrm{T}$ & p.(Arg619Ter) & & \\
\hline & c. $1861 \mathrm{C}>\mathrm{T}$ & p.(Arg621Ter) & & \\
\hline & c. $1877 \mathrm{G}>\mathrm{A}$ & p.(Trp626Ter) & & \\
\hline & c. $1882 \mathrm{C}>\mathrm{T}$ & p.(Arg628Ter) & & \\
\hline & c. $1898 \mathrm{C}>\mathrm{A}$ & p.(Ser633Ter) & & \\
\hline \multirow{7}{*}{$\begin{array}{l}\text { Probab } \\
\text { ly } \\
\text { associ } \\
\text { ated }\end{array}$} & c. $223 G>A$ & p.(Ala75Thr) & & \\
\hline & c. $386-2 A>G$ & & c. $265 \mathrm{C}>\mathrm{T}$ & p.(Arg89Trp) \\
\hline & c. $386-1 G>A$ & & c. $590-7 \mathrm{G}>\mathrm{A}$ & \\
\hline & c.653T $>C$ & p.(Leu218Pro) & c. $1139 A>G$ & p.(GIn380Arg) \\
\hline & c. $979 \mathrm{G}>\mathrm{C}$ & p.(Ala327Pro) & c. $1469 T>C$ & p.(Leu490Pro) \\
\hline & c. $1163 C>G$ & p.(Thr388Arg) & c. $1487 C>T$ & p.(Pro496Leu) \\
\hline & & & c. $1898 \mathrm{C}>\mathrm{T}$ & p.(Ser633Leu) \\
\hline \multirow[t]{4}{*}{$\begin{array}{l}\text { Possibl } \\
\text { y } \\
\text { associ } \\
\text { ated }\end{array}$} & $\begin{array}{l}\text { C.(?_- } \\
\text { 88)_(299+1_300- } \\
\text { 1)del }\end{array}$ & & c. $107 \mathrm{C}>\mathrm{A}$ & p.(Ala36Glu) \\
\hline & $\begin{array}{l}\text { c.(?_- } \\
88 ?) \_(* 136 ?) \mathrm{del}\end{array}$ & & c. $266 \mathrm{G}>\mathrm{A}$ & p.(Arg89GIn) \\
\hline & c. $1 A>G$ * & p.(Met1?) * & $\begin{array}{l}\text { c.398_403delTGGGC } \\
\text { A * }\end{array}$ & $\begin{array}{l}\text { p.(Met133_Gly } \\
\text { 134del)* }\end{array}$ \\
\hline & $\begin{array}{l}\text { c.36_44delGCTCCT } \\
\text { GGC }\end{array}$ & $\begin{array}{l}\text { p.(Leu13_Ala15 } \\
\text { del) }\end{array}$ & $\begin{array}{l}\text { c.523_534delTGGAA } \\
\text { CTTCGAG * }\end{array}$ & $\begin{array}{l}\text { p.(Trp175_Glu1 } \\
\text { 78del) * }\end{array}$ \\
\hline
\end{tabular}

This article is protected by copyright. All rights reserved. 


\begin{tabular}{|c|c|c|c|}
\hline c. $41 \mathrm{~T}>\mathrm{G}$ & p.(Leu14Arg) & c. $536 \mathrm{C}>\mathrm{A}^{*}$ & p.(Thr179Lys) * \\
\hline c. $158+1 G>A$ * & & c.794G $>A$ & p.(Gly265Asp) \\
\hline c. $236 \mathrm{C}>\mathrm{T}$ & p.(Ala79Val) & $\begin{array}{l}\text { c.878_889dupCCCCC } \\
\text { ATTTACA }\end{array}$ & $\begin{array}{l}\text { p.(Thr293_Tyr2 } \\
\text { 96dup) }\end{array}$ \\
\hline c. $250 \mathrm{G}>\mathrm{C}$ & p.(Gly84Arg) & c.956C>T & p.(Ala319Val) \\
\hline c. $590-1 \mathrm{G}>\mathrm{C}$ * & & c. $1598 \mathrm{C}>\mathrm{T}^{*}$ & $\begin{array}{l}\text { p.(Pro533Leu) } \\
*\end{array}$ \\
\hline c.659G $>A$ & p.(Gly220Asp) & c. $1868 \mathrm{~T}>\mathrm{C}$ * & $\begin{array}{l}\text { p.(Leu623Pro) } \\
*\end{array}$ \\
\hline c. $1045 \mathrm{G}>\mathrm{T}$ & p.(Asp349Tyr) & c. $1871 \mathrm{~A}>\mathrm{T}$ & p.(Asp624Val) \\
\hline c. $1728-1 G>C$ & & & \\
\hline c. $1828 \mathrm{G}>\mathrm{C}$ * & p.(Asp610His) * & & \\
\hline \multicolumn{4}{|l|}{ Association not determined } \\
\hline $\begin{array}{l}\text { c.46_57delTCGCTC } \\
\text { CTGGCC }\end{array}$ & $\begin{array}{l}\text { p.(Ser16_Ala19 } \\
\text { del)** }\end{array}$ & & \\
\hline c. $623 G>T * *$ & $\underbrace{\text { p.(Gly208Val) }}_{* *}$ & & \\
\hline c. $1598 \mathrm{C}>\mathrm{G}$ & $\begin{array}{l}\text { p.(Pro533Arg) } \\
* * *\end{array}$ & & \\
\hline
\end{tabular}

* refers to variants for which the suggested association relies on phenotypic information provided from referring clinicians for individuals not reviewed in the Manchester LSD service. ${ }^{* *}$ refers to variants for which associations were not determined but were associated with a severe phenotype when only individuals reviewed in the Manchester LSD service were considered. ${ }^{* * *}$ Homozygosity for this variant was associated exclusively with attenuated phenotypes.

This article is protected by copyright. All rights reserved. 
Table 5: Prediction of phenotypic severity in a test cohort. Test cohort of 31 families originally described by Beesley et al. (2001) and for whom updated genotypes and phenotypic information was obtained (Clare Beesley, personal communication). Individuals had no or only one of nine 'common' variants. Details of test cohort are given in Table S3. Predictions were made on the basis of associations suggested in Table 4. Two nonsense/truncating variants, or 'probably' or 'possibly' severe-phenotype-associated variants were predicted to result in a severe phenotype. Individuals with a genotype with one or more 'probably' or 'possibly' attenuated-phenotype-associated variants were predicted to have attenuated phenotype. A 'strong' prediction was made where the strength of association of both variants was 'probably' associated, whereas a 'weak' prediction was made if the strength of association of one or more variants was 'possibly' associated.

\begin{tabular}{|c|c|c|c|c|c|}
\hline & & & Actual $p$ & & \\
\hline & & & Severe & Attenuated & Totals \\
\hline Predicted & Severe & (Strong) & 14 & 0 & 14 \\
\hline & & (Weak) & 0 & 0 & \\
\hline & Attenuated & (Strong) & 0 & 6 & 7 \\
\hline & & (Weak) & 0 & 1 & \\
\hline & Unable to $p$ & & 6 & 4 & 10 \\
\hline Totals & & & 20 & 11 & 31 \\
\hline
\end{tabular}

This article is protected by copyright. All rights reserved. 